\title{
Las cofradías de pescadores en el País Vasco. Cambios e influencias históricas y actuales en la pesca de bajura: el caso de Santurtzi (Bizkaia)
}

\section{The fishermen's associations of the Basque Country. Changes and historical and current influences in inshore fishing: case study of Santurtzi (Biscay)}

\author{
Juan Antonio Rubio-Ardanaz ${ }^{1}$ http://orcid.org/0000-0002-1613-7058 \\ ${ }^{1}$ Universidad de Extremadura, Departamento de Psicología y Antropología, ESPAÑA. \\ Email: rubioardanaz@gmx.es
}

\section{Resumen}

Las cofradías de pescadores del País Vasco han sido las encargadas de aglutinar, adaptar y dar continuidad a la profesión, en función de los cambios sociales, económicos y tecnológicos de cada momento histórico. La pesca de bajura ha encontrado en estas instituciones la vía para hacer frente a las vicisitudes propias de esta modalidad pesquera en un proceso de continua evolución. El modelo originariamente artesanal cambiará definitivamente entrando en fases de modernización y confluyendo finalmente en las formas de producción actuales dependientes del modelo capitalista en vigor. Para comprender las distintas fases de esta situación hemos estudiado el caso de la cofradía de Santurtzi (Bizcaya).

Palabras claves: cofradía de pescadores, pesca de bajura, cambio económico, gestión, País Vasco.

\begin{abstract}
The fishermen's associations of the Basque Country have been responsible for bringing together, adapting and giving continuity to the profession, depending on the social, economic and technological changes of each historical moment. Inshore fishing has found in these institutions the way to face the vicissitudes of this fishing modality in a process of continuous changes. The traditional model will change definitively entering a period of modernization, finally converging in the current forms of production dependent on the current capitalist model. To understand the different phases of this situation we have studied the case of the fishermen's association of Santurtzi (Bizcay).
\end{abstract}

Keywords: fishermen's association, inshore fishing, economic change, management, Basque Country.

Recibido: 20 julio 2017. Aceptado: 27 marzo 2018 


\section{Introducción}

Ciñéndonos a la parte interior del golfo de Bizkaia, en el Cantábrico oriental, encontramos los territorios históricos de Bizkaia y Gipuzkoa que, junto al de Lapurdi, configuran la parte atlántica litoral del País Vasco. Bajo jurisdicción española los dos primeros y francesa el tercero, comparten vínculos culturales y lingüísticos que en parte se mantienen en la actualidad a pesar de su prolongada adscripción a dos Estados europeos diferentes. Esta pertenencia a administraciones distintas ha influido a lo largo de los años de manera diferencial en la organización y desarrollo económico, tanto en el campo pesquero como en el portuario comercial e industrial. ${ }^{1}$

No obstante, se trata de un escenario en el que está presente una muy dinámica cultura marítima que ha ido impregnando el transcurso cotidiano del país a lo largo de sus diversos períodos históricos. Y que se ha hecho evidente en villas y ciudades portuarias de origen comercial como Bilbao, Pasaia, DonostiaSan Sebastián y Baiona, cuyos puertos empezaron a desarrollarse en época medieval. Haciendo parte de la esfera marítima vasca y también desde antiguo, se muestran asimismo un conjunto de localidades dedicadas a la pesca, tanto de litoral como de altura, las cuales serán objeto de paulatinos cambios y adaptaciones. ${ }^{2}$ Concretamente la pesca de bajura ha

1 El golfo de Bizkaia comprende un amplio litoral que transcurre prácticamente desde el municipio de Fisterra, en castellano Finisterre (en Galicia, provincia de A Coruña) hasta el departamento de Penn ar Bed/Finistère (Bretańa). Se trata de un espacio de costa compuesto por un mosaico cultural a través de territorios como Galicia, Asturias y Cantabria en España, País Vasco en España y Francia, y Landes, Gironde, Charente Maritime, Vendée, Loire Atlantique, Morbihan y Finistère en Francia. No obstante, los colectivos y localidades pescadoras donde se practica la modalidad de bajura vienen presentando correlaciones y semejanzas en sus modos de vida y la organización de la profesión, aspecto patente asimismo a lo largo del litoral cantábrico y más aún al comparar territorios colindantes, como sucede con el País Vasco y Cantabria.

2 Históricamente los pescadores vascos de manera semejante al resto del Cantábrico se dedicaron a la caza de la ballena (Eubalaena glacialis) y otros cetáceos, llegando hasta Galicia. Antes de cruzar el Atlántico también frecuentaron aguas irlandesas. Faenaron en la parte más septentrional de Canadá (Terranova, Labrador) desta- ido evolucionando, llegando a los siglos XX y XXI, mostrando hoy en día formas de vida y ambientes característicos, basados en relaciones propias, tanto entre las personas que habitan los pueblos costeros como entre estas y su medio. ${ }^{3}$

Desde el punto de vista antropológico, comprobamos manifestaciones en las que a primera vista aparecen hombres y mujeres pescadores, organizados y protagonistas de un conjunto de constructos socioculturales configurados en relación con el acceso a los recursos marítimos propiciados a lo largo del litoral. Las relaciones sociales de los pescadores y aquellas que entablan con el medio se hacen patentes en una diversidad de localidades, en el marco de una confluencia social y cultural palpable que pasa a través de intereses principalmente económicos. Hallamos así, un acervo de labores y acciones profesionales que encuentran su correspondencia en un ambiente donde se articulan y entran en juego esferas como la económica (aprovechamiento de los recursos marítimo-pesqueros), la institucional y política (puesta en pie de cofradías y pósitos destinados a la venta, aplicación normativa, gestión de la profesión, servicios sociales y defensa de los hombres y mujeres pescadores) y la simbólica (universo simbólico en relación con el medio marítimo, apropiación de figuras específicas del santoral y ritual católico y festividades).

Nos situamos pues sobre el litoral vasco, pero de una manera puntual en su parte más occidental, donde hemos realizado primordialmente nuestro trabajo de campo antropológico, iniciado ya a principios de

cando la captura de especies como el bacalao común (Gadus morhua) y donde aprovecharon nuevamente la presencia de la ballena, pesquerías ambas que decaerían a mediados del siglo XVII (Huxley [Barkham], 1987).

3 La pesca de bajura no obstante es solamente una de las partes de la esfera marítima de la localidad estudiada, la cual comporta un abanico de dedicaciones cada vez más complejo. Aunque la antropología marítima en gran medida se ha venido ocupando de los pescadoresmarinos o haliéuticos, queda abierta la posibilidad de analizar otras profesiones y labores relacionados con la mar (Geistdoerfer, 2007). En Santurtzi y resto del país la evolución social, tanto de los hombres y mujeres pescadores como de los relacionados con otros ámbitos marítimos, no puede entenderse sino a condición de no separarlos del resto de la sociedad. 


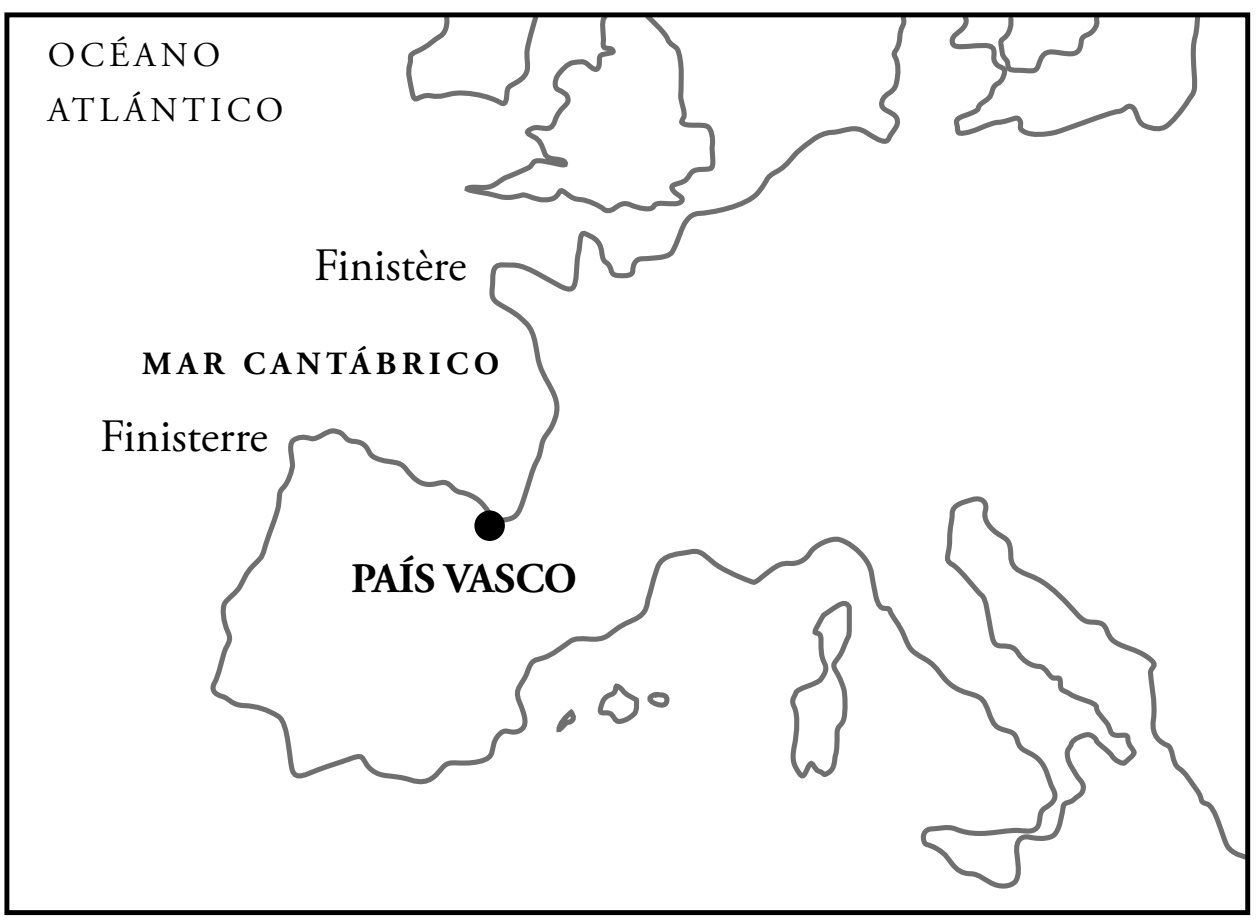

Figura 1. País Vasco en el interior del golfo de Bizkaia.

los años noventa y que llega hasta esta última década, entre los hombres y mujeres pescadores de la localidad vizcaína de Santurtzi, próxima a la ciudad portuaria de Bilbao. De manera semejante a otras localidades pesqueras del país, llama la atención el mantenimiento de una institución fundamental que ha llegado hasta nuestros días, tal y como es la cofradía de pescadores. Este tipo de instituciones han conservado documentación histórica que en algunos casos se remonta al siglo XIV y gracias a la cual hemos podido conocer la forma de organización de la vida de los pescadores (Arizaga Bolumburu, 2000). Se trata de asociaciones de origen gremial, encargadas a lo largo del tiempo de defender los derechos de sus asociados, regulando la pesca y la navegación: defensa de las aguas jurisdiccionales, organización del oficio y de las embarcaciones, las jornadas de trabajo y mareas, la vigilancia del estado de la mar, garantizar la provisión de cebos a las embarcaciones, regulación de las artes de pesca y la venta del pescado. ${ }^{4}$

4 Como veremos en algunas localidades, como sucede en Santurtzi, las cofradías se encargan también de velar por otros trabajos portuarios relacionados con la nave-
En el marco cultural marítimo indicado, y ante una institución como la cofradía, van apareciendo un conjunto de realidades y avatares a los que se hará frente, derivados principalmente de un medio tan aleatorio como el marítimo, el desarrollo tecnológico y la dependencia del mercado. La mar se presenta como fuente irregular de recursos en virtud de condiciones meteorológicas cambiables y de la presencia

gación comercial hasta finales del siglo XIX, momento en el que la gestión y control del puerto comercial e industrial pasan a manos de la administración estatal. En esta localidad, punto clave de acceso al puerto interior de Bilbao, los pescadores realizaban labores de lemanaje, atoaje, amarre y avituallamiento a los buques (Rubio-Ardanaz, 2006, pp. 119-147). A partir de esta fecha será responsabilidad exclusiva de la autoridad portuaria, instancia no pescadora. Sin embargo, ello no será óbice para que parte del colectivo pescador siga compaginando sus labores pesqueras con otras portuarias donde, por ejemplo, durante nuestro trabajo de campo encontrábamos mujeres dedicadas a la venta del pescado, sardineras, que en períodos de escasez, todavía en los ańos cincuenta y sesenta, trabajaron descargando barcos mercantes en el puerto de Bilbao, o más recientemente pescadores con titulación capacitados para trabajar en el transporte marítimo. 
o no de pescado. Al mismo tiempo los pescadores deben responder ante un cambio tecnológico de acceso dificultoso, debiendo cambiar y adaptarse ante las nuevas tecnologías que van a ir apareciendo en el sector. Estos factores jugarán un papel importante, sin olvidar la relación con un mercado en el que deberán poner en circulación su producto. Como veremos, todo ello compondrá un conjunto de factores correlacionados con la cofradía. Desde esta consideración estudiar y llegar a conocer los modos y formas de obtener los recursos materiales, así como los aspectos que se derivan de ello, exige, tal como proponemos aquí, estudiar la evolución de esta institución en las últimas décadas. Para esto planteamos un recorrido cronológico con el fin de descubrir el papel fundamentalmente económico ejercido institucionalmente desde la cofradía perteneciente a los pescadores de Santurtzi, quienes han debido hacer frente y resolver constantemente una diversidad de situaciones marítimo-pesqueras propias de un sector como el de bajura, para poder mantenerse como colectivo profesional que con su presencia marca una parte importante de la personalidad social y cultural del municipio.

\section{Antesala a la modernización de la pesca de bajura}

La modernización de las formas de pesca tradicionales parte de un contexto sociocultural y económico previo característico, propiciatorio de la posterior transformación. Dicho contexto será posible gracias a la presencia de las cofradías de pescadores. Apoyándose en ellas, hombres y mujeres cofrades han aprendido a organizarse para encontrar protección y refuerzo, propiciando situaciones sociales favorables.

Por medio de la agrupación se consigue cohesión, posibilitando la defensa de sus intereses y alcanzando una regulación y condiciones convenientes y beneficiosas para la venta del pescado. Esto será una constante en el tiempo a pesar de las variaciones y cambios que vamos a ir mostrando. Al mismo tiempo encuentran un apoyo ideológico a través del marco simbólico-religioso que se traduce en momentos de festividad, celebración y reparto de beneficios, donde es habitual la presencia de figuras propias del

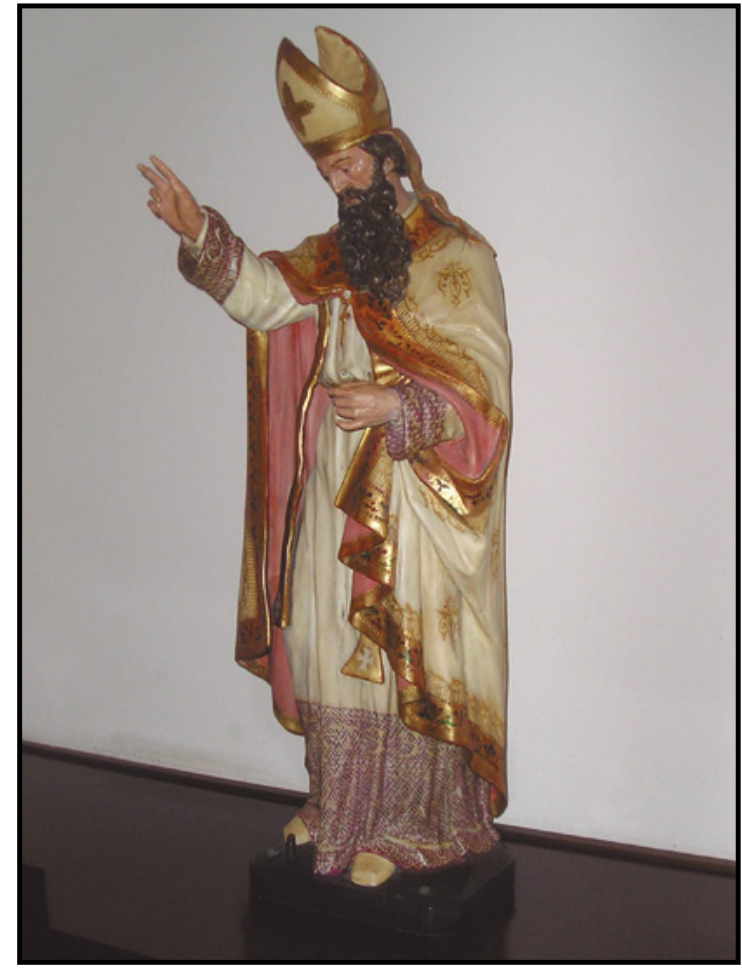

Figura 2. Imagen de San Nicolás Patrono de la antigua Cofradía de Mareantes de Santurce. Parroquia de San Jorge. Santurtzi (2.11.2016).

santoral cristiano, patronos de las cofradías. En Santurtzi y también con frecuencia en otras localidades, han sido San Pedro y San Nicolás, y más puntualmente como en otros pueblos, San Lázaro y Santo Tomás. Este primer binomio aparentemente sencillo en el que entran en juego la cohesión en torno a intereses materiales comunes y el apoyo ideológicoreligioso, a lo largo del tiempo será una constante primordial para la profesión pescadora, cada vez más compleja a la hora de abordar sus vicisitudes y tratar de mantener su permanencia.

\section{Embarcaciones y aparejos tradicionales}

Paralelamente a la presencia institucional, en este momento previo a la modernización, los medios productivos son más bien sencillos. Las embarcaciones utilizadas nos permiten hacernos una idea bastante exacta del tipo de pesca practicada antes de los ańos veinte del siglo pasado. Hasta prácticamente el primer cuarto del siglo, los pescadores de bajura recurren a barcos de tamańos reducidos, 


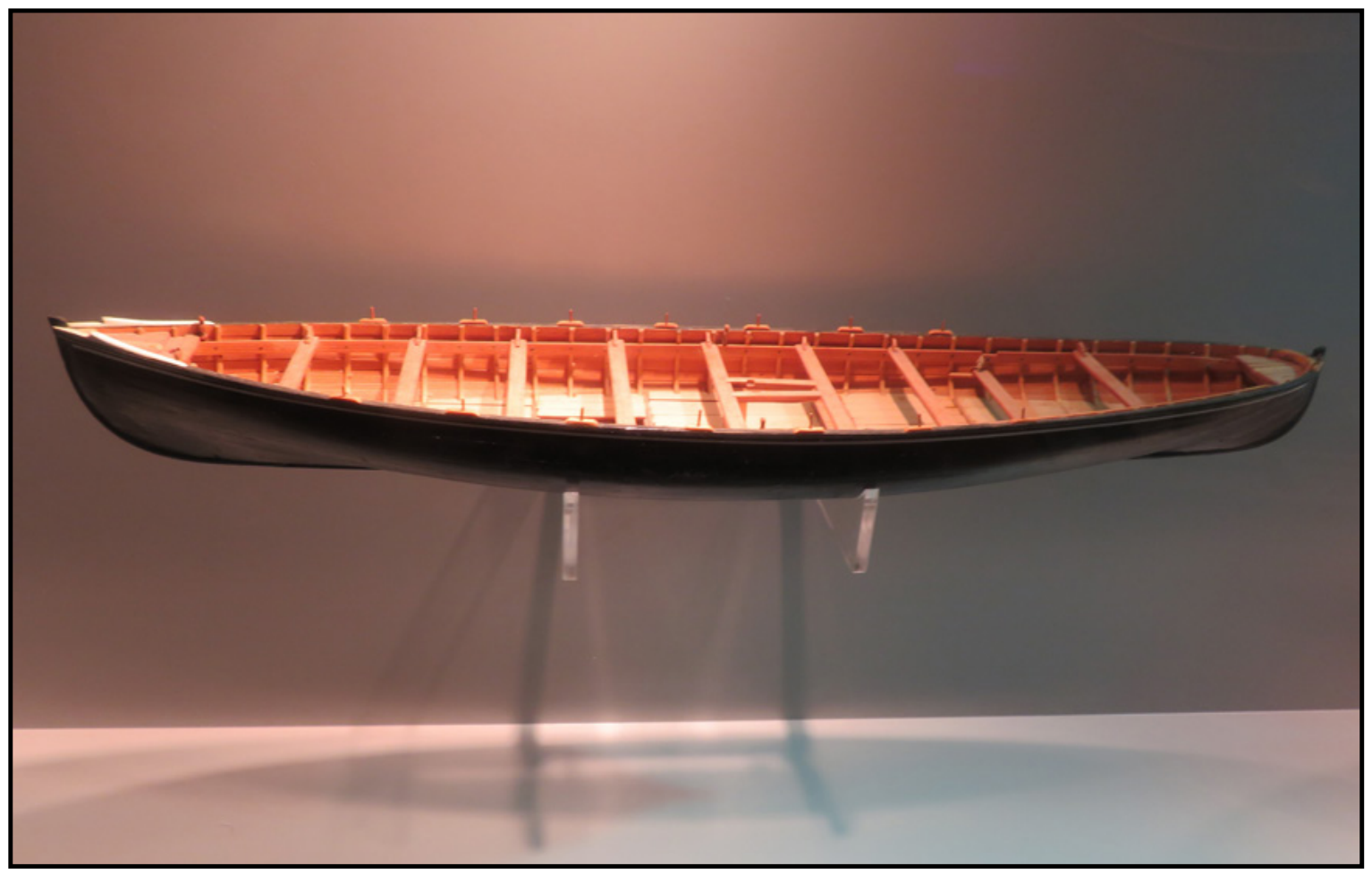

Figura 3. Maqueta de trainera, siglo XIX (Arrantzaleen Museoa, Bermeo. 21.05.2017). ${ }^{6}$

resguardados en sus pequeños puertos, al abrigo del norte y noroeste. En puertos como Santurtzi y en sus vecinos Zierbena, Portugalete y Algorta, todos ellos en el abra o concha de la ría de Bilbao, se sigue un patrón parecido al del resto del litoral vasco y cantábrico en general, donde fueron habituales, tal como indica Apraiz Zallo (1998), embarcaciones como el bote o batel, la lancha sardinera o baideko, la lancha merlucera o potiñ, la trainera y la lancha o txalupa bonitera.

La trainera, totalmente generalizada a finales del siglo XIX, en un principio estuvo destinada al uso de la traína, arte que exigía lanchas ligeras, largas y maniobrables. ${ }^{5}$ Con ella se pescan entre otros, la dorada

5 "El arte norteño, la traína, consistía en una red compuesta por 8 o 10 piezas de malla fina, de unos $2,5 \mathrm{~cm}$ de lado, con unas medidas totales de $35 \mathrm{~m}$ de largo y casi $4 \mathrm{~m}$ de altura en sus extremos. El paño, por su propio peso, se abombaba en el centro, dando a la traína una altura final en el centro de $7 \mathrm{~m}$. La relinga superior se cubría de corchos, y de plomos, la inferior, prolongándose las alas en largos 'tiros' con los que virar el arte” (Arbex y Galindo López, 1987, p. 70).
(Sparus aurata), caballa o verdel (Scomber scombrus), chicharro (Trachurus trachurus), anchoa o bokarte (Engraulis encrasicolus) y sardina (Sardina pilchardus). Son barcos pequeños que apenas superan los $700 \mathrm{~kg}$ y de un diseño "especialmente hidrodinámico con finas líneas de carena, quilla arqueada, pie de roda con amplio radio de curvatura y una extremada ligereza” (Apraiz Zallo, 1998, p. 389).

6 La construcción de las maquetas (Figuras 3, 4 y 6), realizada por modelistas navales, metodológicamente obedece a un riguroso seguimiento de planos reales conseguidos tras una labor de investigación, complementada etnográficamente para obtener el máximo número de detalles recurriendo a informantes (carpinteros de ribera y pescadores) que tuvieron contacto directo con este tipo de embarcaciones. Están fabricadas a escala 1/50, habiéndose seguido no solo los planos (Figura 4), sino también las memorias exigidas para los trámites legales de sus correspondientes registros (Figura 6) y de embarcaciones auténticas conservadas museísticamente (Figura 3). Representan la evolución técnica pesquera y equipamiento al mínimo detalle, cuyas piezas se han construido a escala a partir de los planos mencionados, siendo réplicas exactas y fieles copias de los originales. 
Sus medidas se acercan a los $11 \mathrm{~m}$ de eslora y $2 \mathrm{~m}$ de manga, con puntales de $0,8 \mathrm{~m}$ y una capacidad de entre 4 TRB y 6 TRB. ${ }^{7}$ A la traína le sucederán las redes de enmalle (de $60 \mathrm{~m}$ de longitud y $9 \mathrm{~m}$ de altura) y posteriormente el bolintxi (arte de cerco). Se trata de un barco de rápido manejo, no exento de peligrosidad; ágil e inestable al mismo tiempo: "sin calado, sin cubierta, con una quilla simbólica y sobrecargada por 12 o 14 hombres, más sus aperos, la trainera fue presa de los embates del Cantábrico" (Arbex y Galindo López, 1987, p. 71). Su velocidad y rapidez fueron imprescindibles donde aparejos como la traína y el bolintxi para su largado exigían pericia y rapidez en confluencia con técnicas como la manjua ${ }^{8}$ y el macizo. ${ }^{9}$ En resumen, y como vemos, en su conjunto se trata de recursos aparentemente sencillos y poco complejos, aunque no dejan de implicar un profundo conocimiento del estado de la mar, de las corrientes, de las aves y su forma de alimentarse, etcétera, así como habilidades a la hora de avistar y seguir animales como los tolinos (Tursiops truncatus), los cuales condu-

7 Respecto a la complejidad de este tipo de embarcación Apraiz Zallo (1998, p. 389) indica que su modo de construcción "era bastante simple, con estructura de cuaderna cocida o aserrada de roble, material con el que también se elaboraba la mayor parte de las piezas"; por otra parte "el número de bancadas variaba según los tamaños entre seis y ocho, lo cual también determinaba su tripulación, que podía oscilar entre los diez y los catorce miembros. Carecían de cubierta y tenían la sentina protegida y tapada por panas, prácticamente a lo largo de toda la eslora. Podían arbolar dos mástiles, trinquete y mayor, pero raramente utilizaban ambos simultáneamente, limitándose en la mayoría de las ocasiones a utilizar el trinquete, por lo cual la propulsión se efectuaba generalmente a remo".

8 Manjua o "ir a la manjuada" significa salir a la mar a buscar la manjuada (cardumen que se pretendía capturar). Esta técnica, tradicionalmente opuesta a la del macizo, implicaba la obligación de repartir la pesca de la manjuada entre las embarcaciones participantes, pero en cuya operación sólo intervenía un solo barco (el primero en llegar al punto donde se hallaba el cardumen y en largar el bolintxi). Esta concepción comunal de los recursos desaparecerá a medida que se modernicen los medios de producción (Rubio-Ardanaz, 2002).

9 La técnica del macizo consistía en hacer subir a los peces para su captura, usando un cebo preparado a base de hueva de bacalao, importado de Noruega, de tal forma que al ser lanzado al agua, su flotabilidad, lenta disolución y hundimiento, propiciara la subida del cardumen. cían a los pescadores en la mar hasta los bancos de peces o manjuadas. ${ }^{10}$

En este mismo escenario pesquero tradicional encontramos también, en un lugar destacable, la txalupa o lancha bonitera. Ahora de mayores dimensiones y capaz de perseguir los túnidos que se acercan a la costa vasca, como son el atún rojo (Thunnus thynnus), o hegamotz (que en castellano significa "aleta corta") y el bonito (Thunnus alalunga) o hegaluze (aleta larga), también conocido como atún blanco. ${ }^{11}$ El primero hace acto de presencia entre los meses de marzo y mayo, siendo abundante entre junio y septiembre, mientras que el bonito ha sido abundante entre julio y octubre. Además de túnidos, durante los meses de invierno la principal especie capturada sería el besugo o besigu (Pagellus bogaraveo), pescado con palangres. Estas embarcaciones permitían adentrarse más lejos en la mar, estando también adaptadas a la rapidez y velocidad exigidas por una técnica como el "método de varas" o cacea (también conocido como curricán) utilizado para la pesca del bonito. Este método consiste en arrastrar un cebo artificial sobre los peces, confeccionado tradicionalmente con hojas de mazorca de maíz -y más tarde de plástico- con las que se camuflaba el anzuelo. Para esto se utilizaban varias perchas a modo de cańas desde los costados del barco, mientras el cebo dejaba una estela ante la que los peces reaccionaban picando vorazmente.

Volvemos a constatar en la txalupa una embarcación que responde a un tipo de propulsión, remo y velas (trinquete y mayor), propios de un modelo de pesca a muy pequeña escala comparativamente con lo que sucederá pocos años más tarde. $\mathrm{Y}$ aunque se trata de la de mayor tamańo e importancia, sus medidas oscilarán entre los 12 y los $15 \mathrm{~m}$ de eslora y 3 a 3,5

10 El conocimiento que ostentan los pescadores se brinda como campo de interés. Este ha sido objeto de estudio reciente, por parte de investigadores como E. Carbonell i Carós (2010), quien muestra de manera analítica un conjunto de saberes etnoclimáticos propios del ámbito pesquero artesanal catalán.

11 No hay que confundirlos con otra especie, el atun txiki (Sarda sarda), poco frecuente en aguas cantábricas y procedente del sur, conocido también como bonito en regiones como Andalucía, ni con otra no siempre habitual como el listado, lampo o lanpua (Katsuwonus pelamis). 
$\mathrm{m}$ de manga; de 1 a 1,5 $\mathrm{m}$ de puntal las más grandes y una capacidad de 15 TRB. Barcos con "suave arrufo, forma de uso, líneas bastante llenas y finos pronunciados", hechos "casi exclusivamente de roble", a menudo "sustituido por el pino, principalmente en el forro" (Apraiz Zallo, 1998, p. 390). Como podemos comprender, los medios de producción responden a un tipo antiguo de pesca considerada artesanal, que se sostiene y organiza de forma institucional desde la relativa complejidad propia de las cofradías, antesala de una producción tecnológica y comercialmente más compleja. Esta irá ocupando su espacio en paralelo a una paulatina ampliación de los tamańos de los barcos, con modelos de propulsión mecánica que desplazarán definitivamente el remo y la vela, al mismo tiempo que aparecen nuevos intereses económicos.

\section{Las cofradías de pescadores, institución pesquera primordial}

En este contexto nos interesa comprender más detalladamente el papel y funciones desempeñados por las cofradías, presentes en el país desde antiguo, como hemos señalado más arriba. En algunos pueblos llegan a convivir más de una, siendo la institución social principal. De origen medieval y gremial como también se ha indicado, las más antiguas irán sirviendo de modelo a las demás a medida que pase el tiempo, manteniendo constantemente funciones primordialmente de carácter socioeconómico, fundamentado en la venta del pescado y gestionando las cuentas y en definitiva la profesión, aspectos reflejados en sus normativas y estatutos. ${ }^{12}$ Poco a poco se irán modificando y adecuando a las situaciones económicas, sociales y políticas en vigor (Alegret, 2017, pp. 281-282). De todas formas, los pescadores encontrarán en ellas constantemente un instrumento de poder y cohesión gracias a los cuales se

12 Aunque por nuestra parte y en el caso de Santurtzi solamente hemos encontrado, en la actual cofradía, documentación antigua de mediados y finales del siglo XIX (recopilada en Rubio-Ardanaz, 1992-1993), como indica Erkoreka Gervasio (1991, p. 70), hay pruebas que nos remiten a 1780, año en el que en Santurtzi existe la cofradía como entidad gremial autónoma; este mismo investigador aporta pruebas de su presencia en la localidad, al menos en el siglo XVII. defenderán frente a instancias externas, a menudo de naturaleza gubernamental y municipal que en ocasiones han afectado a sus intereses.

\section{Relaciones con la actividad marítima mer- cante: pescadores y mareantes}

En localidades bajo influencia o relacionadas con el tráfico portuario mercante, como sucede por ejemplo en el abra de Bilbao, prácticamente hasta finales del siglo XIX, además de la pesca, las cofradías regularon trabajos como el atoaje y lemanaje (o $l i$ manaje), antecesores del posterior y actual practicaje portuario. Consistían respectivamente en ayudar en la navegación y maniobras de entrada y salida en el puerto remolcando a los navíos mercantes, y en poner un "piloto lemán" a disposición de los capitanes también en los buques entrantes o salientes.

Los oficios de "pescadores y mareantes" se compaginan y conviven, al amparo de las cofradías que ejercían como garantes, reguladoras y organizadoras. ${ }^{13}$ $\mathrm{Al}$ respecto los cofrades pagan sus cuotas en tanto asociados y participan en los repartos de beneficios anuales (días de San Nicolás, Navidad y Carnaval) y un conjunto de servicios sociales fundamentales. Viene a ilustrarnos la presencia del lemanaje y esta afirmación, el caso de José Loredo en Santurtzi, quien cobra todavía en 1892 "por su participación o sea el de la lancha Joven Felipa que patronea de la Corporación de prácticos del reparto girado el día de San Nicolás último". ${ }^{14}$ Desde cofradías de puertos como este y los de Portugalete, Algorta y Zierbena (los cuatro ribereños al abra de Bilbao) se organizan las tripulaciones, los turnos correspondientes y se acuerdan con el puerto bilbaíno los precios por

13 En estos años en Santurtzi, la cofradía presente aparece bajo la advocación de San Nicolás, venerado en la parroquia de San Jorge, y con el nombre de Cofradía de mareantes de Santurce (Libro de cuentas corrientes de la Cofradía de mareantes de Santurce, 1846); esta precede a la Cofradia Sindical de Pescadores "San Pedro" de Santurce, a la que seguirá la actual Cofradia "San Pedro" de Santurtzi/ "Doneperi” Arrantzale Kofradia. Santurtzi.

14 Información obtenida de los viejos papeles documentales de la actual Cofradia "San Pedro" de Santurtzi/"Doneperi" Arrantzale Kofradia. Santurtzi, recopilada y puntualizada en Rubio-Ardanaz (19921993, p. 228). 
los servicios prestados. Los pescadores además son los mejores conocedores del medio, de su estado según las estaciones del año y de la climatología, aspecto que corrobora nuevamente el amplio compendio de conocimientos generado en el marco de su profesión.

En estos momentos se confirma un carácter claramente proteccionista y aunque los patrones y tripulantes de las lanchas ejercen sus responsabilidades y se atienen a las obligaciones normativas, son las cofradías por medio de sus mayordomos las que velan por el cobro e incluso reclaman, cuando la ocasión lo exige, los pagos no realizados por parte de la autoridad portuaria. Todo lo referente a la asistencia a los barcos mercantes es acordado en "junta de hermandad", desde la asunción de un derecho común que asiste a todos los cofrades. Y bajo esta misma intención proteccionista, las cofradías exigirán y vigilarán para que las tripulaciones estén compuestas exclusivamente por sus miembros. La cofradía, en definitiva, se superpone a los patrones, que quedan supeditados a ella, y trata de ejercer su posición, exigencias y derechos también por encima de las autoridades portuarias.

Comprobamos que la relación trabajo-capital se enmarca en la esfera gremial. Partiendo de un oficio común -mareantes y pescadores-, desde estas instituciones genuinamente marítimas se corporativiza el ejercicio profesional y se controla su organización. No obstante, ya en el siglo XIX chocarán con esferas portuarias exteriores, enfrentándose a un ámbito diferente, como el portuario-mercantil, al que no tendrán más remedio que vender paulatinamente su fuerza de trabajo. Los precios por los servicios a los buques mercantes vendrán fijados desde el puerto comercial, dando lugar a una dependencia que en ocasiones llegará a traducirse en negativas y atrasos en las retribuciones. En este periplo de finales de siglo a pesar de esta subordinación, la cofradía de Santurtzi reclamará por los impagos, asumiendo no obstante tarifas y precios impuestos desde el exterior del colectivo mareante y pescador. Finalmente, la Junta de Comercio, organismo encargado de la gestión del puerto de Bilbao bajo normativa estatal, monopolizará la organización de esta clase de labores que acabarán totalmente desligadas de la esfera pescadora.

\section{Venta y normativa: pago de derechos}

En lo que respecta a la pesca, también se irán produciendo cambios a medida que se vaya incrementando la influencia estatal y liberalizando el sector, desapareciendo poco a poco prácticamente todas las características de raigambre gremial. No obstante, a finales del siglo XIX y principios del XX, la producción pesquera cercana o relativamente alejada de la costa (bajura) se ejerce todavía en un cuadro de tipo exclusivista, en el que se otorga control directo sobre la comercialización del pescado y se limita al mismo tiempo la iniciativa privada (Rubio-Ardanaz, 1997, pp. 302-314). La subasta en la lonja de la cofradía o la declaración de las cantidades y precios del pescado vendido se imponen como obligación. De todas maneras, los pescadores locales reciben un tratamiento preferencial en comparación con los foráneos. Los primeros encuentran protección y mejores condiciones, un pago de derechos por la venta de su pescado mínimo (menores porcentajes) que, sumados a los pagados por los pescadores procedentes de otros puertos (mayores porcentajes), permiten en parte sustentar la institución, cubrir sus servicios y lograr los beneficios repartidos anualmente. Cuando no se vende en la localidad de origen, se deberán pagar mayores derechos por las ventas. Estos derechos se aplican también en función del tamaño de las embarcaciones: las mayores abonarán más dinero que las pequeñas. Este mismo control y exigencias se hacen extensivos cuando se venden las pescas en puertos donde no existe cobro alguno, debiéndose pagar en la cofradía de origen; lo mismo ocurrirá en caso de ventas a las industrias procesadoras de pescado.

Este funcionamiento tendiente a la defensa de los pescadores locales practicado en Santurtzi y resto de cofradías, no obstante admitía convenios y acuerdos entre ellas. Por esta vía se concertaban tratamientos y relaciones basadas en la reciprocidad, consistentes en aplicar los mismos derechos (porcentajes abonados por cantidad de pescado vendido) y unas condiciones equiparables entre distintos puertos. En caso de necesidad de consumo local, se imponía la venta en Santurtzi, norma que garantizaba el acceso al pescado en tanto fuente de alimentación para los lugareños. Con esta normativa se hacía frente a la competencia de las fábricas, siempre muy interesadas en 
adquirir pescado, quedando así totalmente neutralizadas. A pesar de su influencia y poder competitivo, estas pasaban a un segundo plano, quedando anulada cualquier posibilidad preferente, neutralizándose cualquier oferta de pago ventajoso, particularmente beneficioso para los pescadores (modelo económico que no persigue una máxima capitalización, sino la defensa corporativa de las cofradías). Este tipo de normativas desaparecerá posteriormente ante el contexto y condiciones de un mercado liberalizado.

\section{Prestación de servicios sociales}

La protección de los cofrades toma forma a través de un conjunto de prestaciones sociales, atendidas gracias a los beneficios obtenidos por medio de las cuotas de adscripción, el pago de derechos por la venta del pescado, los intereses de préstamos y la inversión de capitales en instituciones financieras. Por estos medios se consigue generar recursos que van a proyectarse en una serie de servicios sociales prestados a los hombres y mujeres pescadores.

Entre los principales aparece el médico-sanitario. Por medio de una "escritura de contrato" anual, se establecen las condiciones que garantizan la presencia de un médico encargado de atender a los cofrades y sus familias, y también a las viudas y huérfanos siempre y cuando mantuvieran sus derechos y residencia en la localidad. En este tipo de escrituras se fija el precio y la forma de pago que, por ejemplo, en esta localidad vasca en 1888 se realiza trimestralmente, ascendiendo a mil pesetas por el año contratado. Igualmente, recibiría su retribución correspondiente, en caso de otro género de asistencias como operaciones de cirugía mayor, consultas, partos y vacunaciones. El médico será quien decida el número de visitas diarias a los enfermos según "su prudencia y celo" en función de la "gravedad e importancia de los enfermos". ${ }^{15}$ La cobertura médico-

15 A partir de la vieja documentación de cofradía santurtziarra ya referenciada, podemos pormenorizar los precios de estos servicios: "por vacunación cincuenta céntimos de peseta por persona. Por asistencia á partos cinco pesetas. Por cada consulta veinte y cinco pesetas; y por las operaciones de cirugía mayor, lo que convenga este Señor facultativo con las familias interesadas”. El médico contratado en 1888 fue "el profesor Don Francisco López", habiéndolo sido anteriormente Mariano sanitaria se extiende y comprende también los gastos farmacéuticos, ${ }^{16}$ así como la asistencia material por medio de un socorro monetario en caso de enfermedad certificada médicamente.

Como vemos, se trata de una asistencia social bastante avanzada para una época en la que aún restaban muchos años en el País Vasco para contar con una atención médica pública universal. Los servicios sociales dispensados por la cofradía también se hacían extensibles al ámbito religioso, corriendo con los gastos producidos por los funerales de aquellos cofrades fallecidos y sus esposas. Estos comprenden parroquia, carpintero y enterrador (funerales de tercera clase). ${ }^{17}$ En ocasión de desgracias en la mar con víctimas mortales, igualmente se sufragan todos los gastos, tal como sucede con el funeral por los once fallecidos en el naufragio de la lancha Joven María, celebrado solemnemente (funeral de primera clase) el 14 de enero de 1888. En él, junto a los del pueblo, llegan a intervenir más de catorce sacerdotes traídos desde Bilbao, Algorta, Desierto y Sestao, quienes reciben pago y manutención. ${ }^{18}$

Villanueva. En él consta literalmente que "En las enfermedades sifilíticas secretas y en las que fuese llamado para su asistencia facultativa por consecuencia de mano airada, cobrará los derechos que considere justos el facultativo" (Escritura de contrato médico y sus bases, 1888).

16 En los libramientos por gastos farmacéuticos en 1888 constan los servicios de la Farmacia de Picatoste, abonados a Manuel Picatoste (Rubio-Ardanaz, 1992-1993, p. 194).

17 Por ejemplo, se paga el funeral celebrado en San Jorge del cofrade Casimiro Careaga, el 12 de enero de 1988, fallecido el día anterior, el cual incluye "Derechos del Clero, fábrica, sacristán, monaguillo y cantor” (17,75 pesetas); "Luces del catafalco, altar y Misa cantada" (7 pesetas): y pago "A la sacristana por servicio de catafalco (3 pesetas). Firma el libramiento el cura Eusebio de la Fuente. Los gastos funerarios en este caso incluirían también el ataúd encargado a la Carpintería de Manuel Garmendia (20 pesetas) y el enterramiento (2 pesetas). En la misma iglesia se celebra el funeral de los también cofrades Tomás Pascual, Martín Hisal, Francisco Recalde, Alberto Iriarte, Antonio García y Lino Celestino Gutiérrez, fallecidos este mismo año (Rubio-Ardanaz, 1992-1993, p. 195 y ss.).

18 La comida de los sacerdotes venidos de fuera ascendería a 49 pesetas, cobrada por Melchor de Urionabasterrechea, a cuyos gastos se suma la comida del Sr. Comandante y sus acompańantes procedentes de Bilbao, total de 120 pesetas (Rubio-Ardanaz, 1992-1993, p. 195 y ss.). 
Además de las esferas sanitaria (atención médica y farmacológica) y religiosa, se atiende la festiva (vehiculada formalmente en correlación directa con las creencias y prácticas católicas). En Santurtzi, uno de los "festejos" principales celebrado corresponde al día de San Nicolás, patrono de su cofradía, la cual correrá con los gastos de la misa mayor correspondiente, que en 1888 costaba 39,75 pesetas. Esta se celebraba en el altar dedicado al santo, existente en la parroquia de San Jorge, en aquellos años ubicada junto al puerto pesquero. A principios de siglo, este último se traslada hacia el exterior ganando así en calado y accesibilidad. Parte de la celebración transcurre en el templo, pero también ocupará el espacio público en la calle, con música y supuestamente el baile, gastos asumidos igualmente por la cofradía que ese mismo año ascendían a 100 pesetas. ${ }^{19}$ Los cofrades llamados a la Armada para cumplir el servicio militar también encuentran asistencia recibiendo una gratificación.

\section{Primeros alejamientos del marco productivo tradicional: aparición del vapor}

El remo y la vela dejarán de ser laboralmente competitivos ante la irrupción de los primeros pesqueros propulsados a vapor. ${ }^{20} \mathrm{~A}$ partir del primer cuarto del siglo XX, ya los pescadores comienzan a alejarse del viejo cuadro adaptativo marítimo dependiente de sus barcos de vela y remo descritos más arriba (traineras y lanchas). Se van a sustituir por nuevos modelos con los que faenar. Estamos pues ante un cambio decisivo y directamente relacionado con la fase de navegación y extracción, momentos primordiales en el proceso conducente a la obtención de sus recursos materiales.

19 Dicho pago lo recibe Antero Puy, el 6 de diciembre, "por la música del pueblo en el día de hoy, fiesta de San Nicolás ajustada por Mayordomía por acuerdo de la Comisión" (Rubio-Ardanaz, 1992-1993, p. 205).

20 Continúa siendo competitivo únicamente a nivel deportivo. Habiendo tenido sus raíces en el mundo pesquero y marinero, sus protagonistas, los mismos pescadores, bogaban con los mismos barcos, remos y ropa con los que salían a faenar, por lógica sin necesidad de entrenamiento previo.
Esta importante novedad ahora permite prescindir de una parte muy significativa del esfuerzo físico, tanto para navegar como para llevar a cabo las maniobras de pesca y el uso de los aparejos. Pero conllevará un sobreesfuerzo de adaptación al tener que aprender a pescar con técnicas desconocidas. Proseguir con la profesión significa ahora la adquisición de nuevos conocimientos y habilidades. En definitiva se trata de controlar y afrontar una nueva forma de producción. Todo ello bajo el constante amparo de las cofradías, pero donde irán apareciendo e implicándose otras instancias y organizaciones con nuevos intereses financieros. Los armadores deberán recurrir a ellas para poder acceder y adquirir los nuevos medios de pesca. Pescar significará, comparativamente con la etapa anterior, la adopción de saberes y dominios totalmente innovadores, así como la implicación con nuevos agentes en el mercado, procedentes del ámbito tecnológico y financiero.

El vapor comienza a difundirse hacia los demás puertos pesqueros vascos desde el puerto labortano de Donibane Lohitzun/Sain-Jean-de-Luz (Arbex y López Galindo, 1987, p. 79), estando presente en las localidades más occidentales como Santurtzi, ya en los ańos veinte. $\mathrm{Y}$ aunque en un principio los vapores conviven con las formas de propulsión anteriores, pronto serán el recurso dominante (ayudándose ocasionalmente de velas). En sus primeros momentos estas nuevas calderas también se instalan en los viejos pesqueros con mayores esloras, pero pronto se irá generalizando la llegada, incluso desde Francia e Inglaterra, de barcos expresamente concebidos y preparados para albergar las nuevas máquinas, en sus inicios de tan solo $12 \mathrm{CV}$.

A pesar del peligro, porque explotaban en ocasiones causando accidentes incluso mortales, ahora aumentan las posibilidades de acudir y adentrarse más lejos en la mar, en embarcaciones más sólidas para la navegación y capaces de conseguir capturas significativamente mayores, así como faenar con todas las artes de pesca habituales. Tiene lugar una pequeña división del trabajo ante la necesidad de un pescador encargado específicamente de la caldera, y se intensifica la presencia de armadores, propietarios

21 Véase la nota 7. 


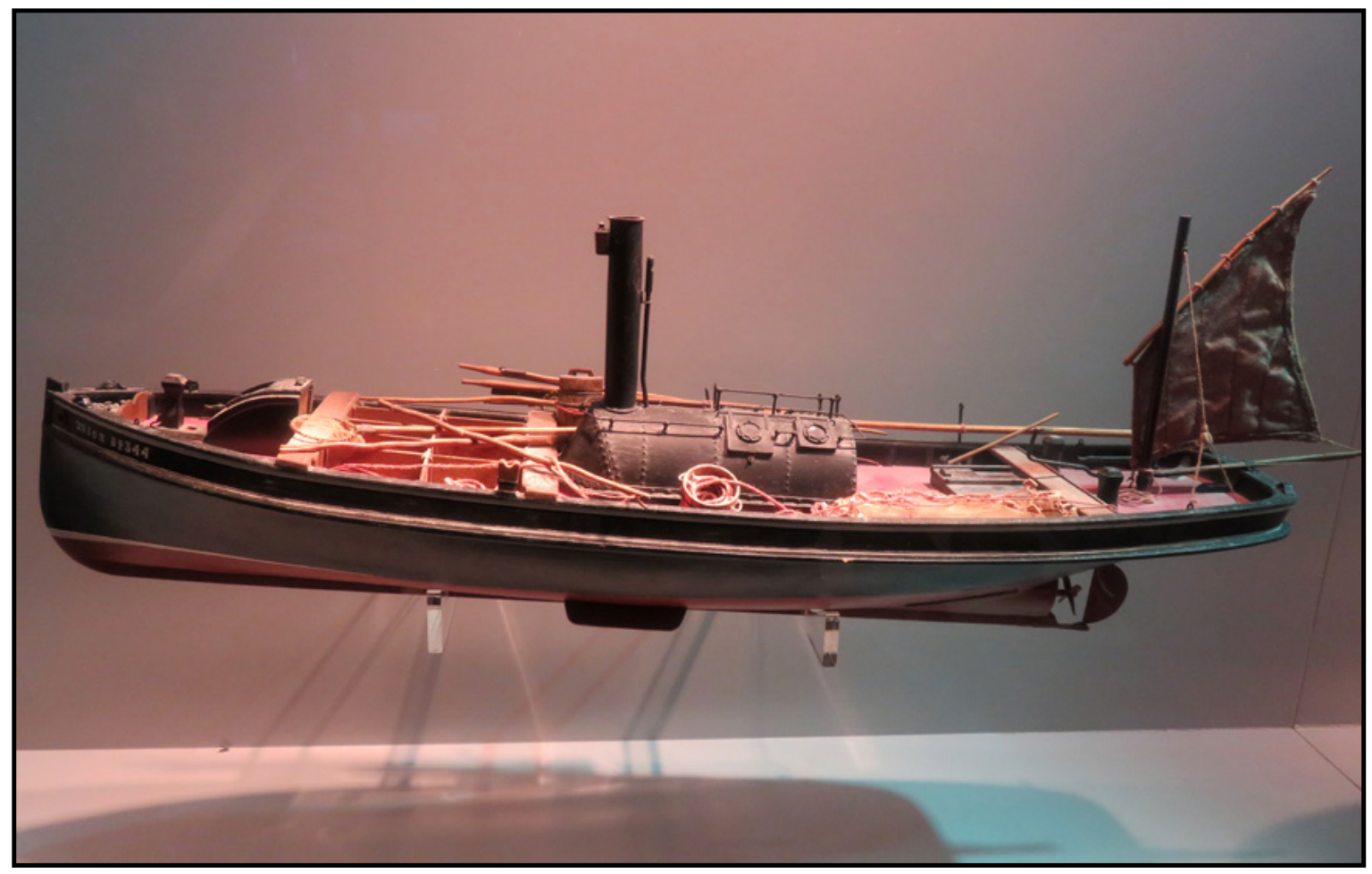

Figura 4. Maqueta de pesquero propulsado a vapor, primer cuarto del siglo XX (Arrantzaleen Museoa, Bermeo. 21.05.2017). ${ }^{21}$

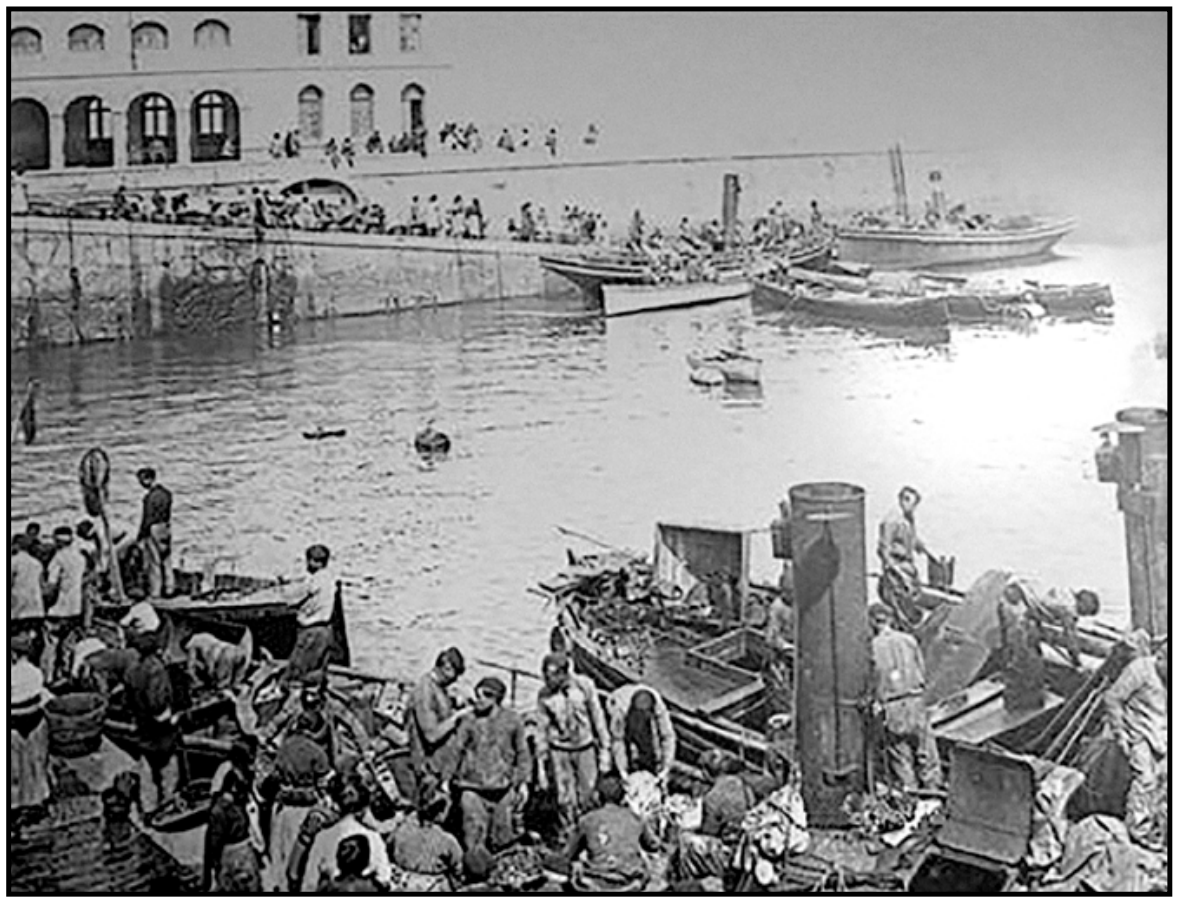

Figura 5. Sardineras y pescadores desembarcando pescado de las lanchas y vapores en el puerto pesquero. Al fondo el edificio de la cofradía (Santurtzi, ańos veinte del siglo XX). 
de los nuevos pesqueros, algunos no necesariamente pescadores y que junto a los patrones-armadores comienzan a capitalizar el sector. Los nuevos vapores son caros y su combustible también, comparativamente con lo conocido hasta el momento. De todas formas, las calderas también serán objeto de cambio, reduciéndose y dejando espacio a motores más reducidos y ligeros. Hasta los años cincuenta del siglo $\mathrm{XX}$ se seguirían construyendo pesqueros de vapor que ya en estas fechas llegarán a alcanzar esloras de $20 \mathrm{~m}$ y mangas de 4,7 $\mathrm{m}$ con motores cuya potencia alcanzaba los $50 \mathrm{CV}$, capaces de proporcionar velocidades en torno a los 9 nudos.

\section{Innovaciones sociales y cambios en la motorización de las embarcaciones}

Siguiendo con la tipología de los barcos pesqueros y su progresión y variaciones a través de los años, así como con los recursos tecnológicos utilizados, podemos volver a comprobar nuevos matices en las formas de producción. Ya en la década de los años treinta, contamos en el país con los primeros motores de explosión y diésel, máquinas más ligeras y de menor volumen. Se trata de ventajas novedosas que traerían modificaciones en la línea de los cascos que ahora dejan de ser panzudos, pasando a un afinamiento considerable de las carenas y a un aumento del calado y del espacio interior.

Tecnológicamente, con el paso del tiempo se empiezan a emplear viveros en los que trasladar cebo vivo destinado a la pesca del bonito con cańa. Nuevamente aumentan los tamańos de los pesqueros quedando desplazados definitivamente los vapores. A partir de los años cincuenta las esloras superan ya los $20 \mathrm{~m}$, con mangas también cada vez mayores (ya en la década de los sesenta en torno a los 4,6 m y $6,2 \mathrm{~m}$ ). Dando un salto realmente cualitativo, las boniteras "se equipan con motores de $300 \mathrm{CV}$ de potencia y 4 o 6 cilindros". Estas representarán la "embarcación reina de la flota cantábrica de bajura". Se trata de la "bonitera polivalente", cuya flota alcanzaría (en 1982), 580 embarcaciones "repartidas a lo largo de la costa Norte, pero con una mayor presencia en las dársenas vascas" (Arbex y López Galindo, 1987, pp. 82-83).
Con el fin de paliar de nuevo el sobreesfuerzo que vuelve a suponer la introducción de nuevos motores, modalidades de navegación y de pesca en general, durante los años cincuenta, en Santurtzi funcionan la "Escuela de Orientación Marítimo Pesquera" y la "Elemental de Pesca". De este modo, en la primera se preparan anualmente algunos pescadores con el fin de obtener los títulos de Patrón de Pesca de Altura, Bajura y Mecánico (incluso de Fogonero Habilitado, aún en 1951). En la segunda reciben formación nińos y jóvenes. En 1954, como en años anteriores, esta "sigue funcionando con 'normalidad y aprovechamiento", recibiendo en esta ocasión "del Iltre. Instituto Social de la Marina para celebrar la Festividad de los Reyes Magos de 1955 la cantidad de 500,00 pesetas que han sido distribuidas en útiles de enseñanza para los niños que asisten a la mencionada Escuela” (M.C.P.S., 1955, p. 4).

A medida que se van modernizando los barcos, aumentan las exigencias tecnológicas y las ansias de mayor productividad, pero al mismo tiempo se exigen titulaciones y preparación oficial para poder salir a la mar. Para paliar esta cuestión la Delegación del Instituto Social de la Marina de Bilbao, con fondos del Patronato Nacional de Protección al Trabajo, organiza cursillos para Motoristas Navales. En el curso 1966-1967 estudian 15 alumnos santurtziarras de los cuales 12 aprueban sus exámenes realizados en la Comandancia Militar de Marina. Esta dinámica proseguirá en el curso siguiente, aprobando otros 12 nuevos Patrones de Pesca de Litoral, cubriendo así las necesidades de este puerto. No obstante, la preocupación al respecto seguirá siendo patente:

Con la modernización de la flota pesquera y correspondiente aumento de tonelaje, así como los desplazamientos a zonas lejanas de pesca, se hace necesario disponer de Patrones de Pesca de Altura, lo cual debido a no disponer de Escuela de Pesca en Santurce, se hace muy difícil. Esperamos que una vez terminada la Escuela de Náutica, que se está construyendo muy cercana al puerto pesquero, podamos conseguir que nuestros pescadores puedan obtener en la misma el título de Patrón de Altura (M.C.P.S.,1967, p. 2). 


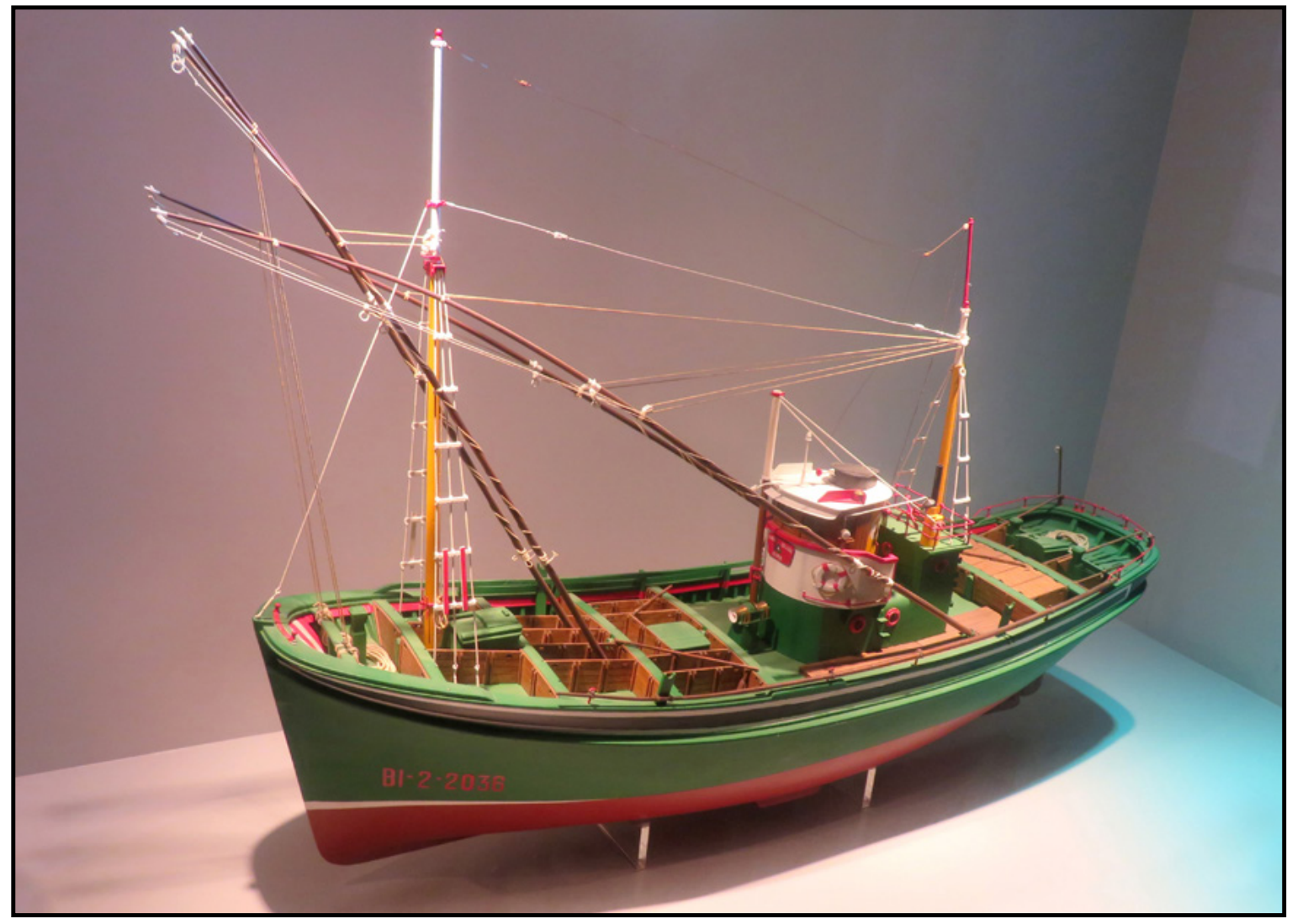

Figura 6. Maqueta de pesquero pertrechado para la pesca del bonito por el método de varas o cacea (Arrantzaleen Museoa, Bermeo. 21.05.2017). ${ }^{22}$

Como vemos, a mediados de los años sesenta se ha entrado definitivamente en una situación diferente en cuanto a exigencias profesionales. Es una dinámica de carácter circular, en la que son necesarios pescadores titulados en función de los nuevos barcos de mayor capacidad, que a su vez necesitan realizar mayores capturas. Se va configurando así un nuevo sistema en el cual, de todas maneras, ni podrán entrar ni tampoco participar todos los armadores.

\section{Desuniformidad de la flota, cálculos presupuestarios y aleatoriedad}

Siguiendo con el modelo presente en Santurtzi, en 1948 su cofradía contaba con una flota de 36 embarcaciones, sin embargo, no son ni de tamaños ni tecnológicamente uniformes. Esta diferencia se traduce en los resultados referentes al importe bruto de

$22 \quad$ Véase la nota 7. pesca subastada en la lonja cuyo $50 \%$ corresponde solamente a siete pesqueros (Pepita, Ignacio Urtiaga, Rosario Elsa, Mari Tere, Dos Amigos, Loli Mila y Mari) de los cuales solamente dos capturan y obtienen el 22\% del total del importe bruto de la pesca subastada en la cofradía (Pepita e Ignacio Urtiaga). ${ }^{23}$

23 A este segmento le sigue otro compuesto por otros ocho pesqueros cuyos importes oscilan entre el 4 y el 2,5\% y que en su conjunto suman el $24,6 \%$ del total (por orden de importancia son las embarcaciones Gaviota, Rosita, Felipa, Anade, Agur Miren, Sota, Ángeles y Juan Andrés). El siguiente segmento de pesqueros lo configuran otros nueve cuyas cantidades oscilan entre el 2,1\% (de aquel que obtiene el mayor importe) y el 1,5\% (correspondiente al menor); entre estas, nueve alcanzan el 16,2\% del total (son San Pedro, Asunción, Lolita, Curosina, Virgen del Chanteiro, Jesús Ignacio, San Antonio, Maria Luisa y Akarregui). A estas le sigue un cuarto segmento compuesto por seis pesqueros que oscilan individualmente por embarcación entre el 1,37 y el $1.03 \%$ obtenido, sumando entre los seis barcos, el 6,9\% del total 
Las embarcaciones de este puerto, por cantidades, consiguen principalmente peces como chicharro (o jurel), anchoa y sardina, los tres en primer lugar (suponiendo el $94,8 \%$ de las pescadas y subastadas. En segundo lugar, está una especie como la boga (Boops boops) (pero que tan solo supone el 2,94\%), y en tercera posición pancho (Pagellus acarne) y bonito ${ }^{24}$ (ambos suman el 1,65\%). Por último, se pescan besugo, verdel, aguja (papardón o paparda) (Scomberesox saurus) y palometa (Trachinotus ovatus) (entre estas cuatro hacen el 0,58\%). El chicharro es la especie más vendida (44,98\%), luego la anchoa $(35,74 \%)$ y la sardina (14\%), esta última en claro descenso año tras año, a pesar de haber sido una especie clave para la localidad.

Este esquema será muy semejante durante los años cincuenta, aunque poco a poco se constatará un número menor de barcos (en 1950 son 29), aunque a medida que se vayan modernizando y aumentando el tonelaje, serán capaces de mantener y mejorar los rendimientos. Los resultados muestran una intensificación de la pesca, coincidente con momentos de escasez de ciertas especies (aun cuando no disponemos de datos, probablemente exista alguna relación). En esta década aparece una inquietud ante la escasez de un pescado considerado "tradicional", expresada entre otras formas de la manera siguiente desde la cofradía:

Nuestro puerto pesquero que casi exclusivamente y desde tiempo inmemorial constituye su medio de vida la captura de sardina, se vé afectado casi considerablemente año tras año por la escasez de la citada especie. Particularmente en nuestra habitual zona pesque-

(son San Francisco de Asis, Joven Elena, Maite, Arrizabalaga, Virgen del Milagro y Juan Ángel). El penúltimo segmento lo componen cuatro barcos, cuya obtención individual oscila entre el 0,76 y el $0,59 \%$, sumando los cuatro, el 2,67\% del total (Tina Gabi, E, Nela y Virgen de Guía). El último segmento lo conforman dos pequeńos pesqueros que obtienen tan solo el 0,048 y 0,028\% y suman el 0,076\% del total (son Santa Teresa y María de los Ángeles).

24 En la contabilización del bonito vendido en la cofradía santurtziarra no se distingue entre el atún rojo y el bonito (atún blanco) propiamente dicho, este último apuntado ocasionalmente como albacora (Thunnus alalunga). ra, habiendo mejorado algo tal anormalidad en la campańa o costera del ejercicio a que hacemos referencia si la comparamos con la del año 1950 que fué francamente adversa, representada por un valor global de subasta de pesca de 2.797.053,25 pesetas (M.C.P.S., 1951, p. 2).

En dicho ejercicio aumenta un $42,2 \%$ en comparación con el ańo anterior y en total se venden, procedentes tanto de los pesqueros locales como de los forasteros, $425.258 \mathrm{~kg}$. Representa el 28,7\% del total de la cantidad de pescado subastado, pero como decíamos la crisis de la sardina perdurará durante esta década a pesar de las vedas establecidas. ${ }^{25}$ En cuanto al valor, dicha especie sigue ocupando el primer lugar, precedida de la anchoa, el chicharro y el bonito. La disminución de manera constante en aguas del abra de Bilbao afectará al suministro de raba de macizo, sensiblemente menor. Ante el macizo, técnica asumida y practicada tradicionalmente, se hace más acuciante la preocupación existente, pues "ante la escasez de dicha especie, los pescadores se abstienen de cebar en abundancia en la seguridad que si lo hicieran, generalmente el importe del pescado no compensaría el gasto de cebo tirado al mar" (técnica del macizo ${ }^{26}$ (M.C.P.S., 1952, p. 2).

La sardina, junto a "otros pescados menudos", es fundamental para las embarcaciones más pequeñas, y sus armadores afrontan con dificultad los "quebrantos económicos tan considerables de esta anormalidad" ${ }^{27}$ Como solución se aconseja desde la

25 En la costera de 1954 se da una sensible mejora achacada a la veda establecida el año anterior y que había proseguido durante 1954 entre el 15 de febrero y el 30 de abril. Sin embargo, al año siguiente la situación volverá a ser calificada de "caótica"; bajando las ventas de $857.903 \mathrm{~kg}$ a tan solo $52.382 \mathrm{~kg}$. Este año se apunta la albacora entre las especies capturadas.

26 La raba, importada y servida por Arbaiza y $\mathrm{C}^{\mathrm{a}}$, es un producto caro que, en opinión de la cofradía, "tendría una gran solución en precio y facilidad de adquisición si se obligase a los Armadores Pesqueros de Altura Españoles a que destinasen la hueva de bacalao y merluza a conservarla para destinarla a cebo de la sardina en la seguridad que bien preparada en nada desmerecería de la importada de Noruega" (M.C.P.S., 1955, p. 2).

27 En 1956 los armadores de los barcos más pequeños no serán capaces de cubrir los gastos materiales de raba, 
cofradía "ir enajenando" las pequeñas embarcaciones de gasolina, "reemplazándolas, aunque fuese en menor número, por otras de mayor tonelaje y radio de acción", con la idea de que se dediquen a las campańas de anchoa y bonito, "que vienen siendo en la mayoría de los puertos de nuestro litoral de resultados muy halagüeños". Este consejo coincidía con el exitoso resultado, comparativamente con ańos anteriores, con el que se conseguía doblar el valor de las capturas para estas dos últimas especies (M.C.P.S., 1956, p. 2). El consejo se traduce en una especie de huida hacia adelante en la que la ambición no deja espacio al más mínimo planteamiento de sostenibilidad. Se trata de una pretensión que de todas maneras dependerá de las posibilidades económicas $\mathrm{y}$, en última instancia, de la decisión de los armadores de los barcos pequeños que no serán capaces de seguir el ritmo de la forma de producción a la que se ha llegado en estos ańos. Este otro aspecto de desuniformidad se traducirá en la convivencia de dos formas económicas de pesca diferentes, en la que estará la practicada finalmente por los barcos de "artes menores" y los de "artes mayores", como veremos más adelante.

\section{Intensificación de los servicios sociales y mejora en las condiciones de vida}

Las cofradías siguen aplicando los derechos o porcentajes cobrados por el pescado vendido en sus lonjas, pero ahora en directa relación con sus presupuestos y objetivos encaminados a maximizar los beneficios en coincidencia con la forma productiva capitalista de las embarcaciones mayores. Esta relación también es extensible a las condiciones del medio. Siguiendo con el caso santurtziarra, en las costeras de 1950 y 1951, por ejemplo, influenciados también por su escasez, se decide un aumento del 5 al 6,50\% en las campańas de sardina, "puesto que una producción mediana de venta global es insuficiente para cubrir el presupuesto de gastos de la Cofradía”. En esta línea la productividad de los barcos grandes se hace cada vez más necesaria para la sostenibilidad de la institución, conjugando para ello objetivos y presupuestos. Es muy interesante comprobar cómo se siguen manteniendo formas

reparación de artes, etcétera, habiéndose vendido tan solo $26.100 \mathrm{~kg}$ de sardina. de relación especiales, en las cuales el vecino puerto de Zierbena recibe un tratamiento diferente, justificado en consideración de su pequeño tamaño que "no tiene medios de absorción del pescado y han de acudir habitualmente al nuestro", razón por la cual "se les descuenta solamente el 3\% (M.C.P.S., 1951, p. 2).

Estamos en un momento en el que además se percibe un salto cualitativo respecto a los servicios dispensados a los cofrades (en esta década en torno a los dos centenares). La atención sanitaria ya no se establece a través de un acuerdo escriturado entre el médico y la institución, sino que se suscribe el denominado "Seguro Obligatorio de Enfermedad en la Industria Pesquera de Bajura a la Parte". Y aunque quedan sin cubrirse "algunas prestaciones médicofarmacéuticas a viudas de pescadores", y dicho seguro no es extensivo a todas las personas, la cofradía se hace cargo de todos los gastos. Por otro lado, se mantiene una "Sección de Ancianidad" propia e independiente, que dedica prestaciones a aquel pescador que al cumplir los sesenta años "quede inactivo en faenas de pesca".

En estos años se afronta la situación de la habitación de los pescadores, en un ambiente de clara modernización. En lugares como Santurtzi, estos han venido ocupando pequeñas casas habitualmente de tres plantas (baja, piso superior, y pequeño camarote o altillo), disponiendo en ocasiones de una pequeña huerta cercana o adosada a la casa, un pequeño kortino (pequeńa cuadra destinada a la crianza de uno o dos cerdos) y gallinero. Son viejas, mantenidas deficitariamente y que apenas responden a las comodidades y exigencias de higiene mínimas que se van imponiendo a medida que mejora la urbanización de los pueblos costeros. El municipio participará un plan a nivel estatal de mejora de la vivienda pescadora. El mes de agosto de 1951, la cofradía, responsable de la gestión, entrega ya las últimas de una primera fase de construcción: "resto de las $\mathrm{Vi}$ viendas Protegidas del Poblado de Pescadores, constituido por 102 viviendas y dos tiendas, humanitaria obra social a favor de la clase pescadora que dispone de vivienda sana y confortable, orientada al mar en una zona envidiable de esta localidad" (M.C.P.S., 1951, p. 2). 


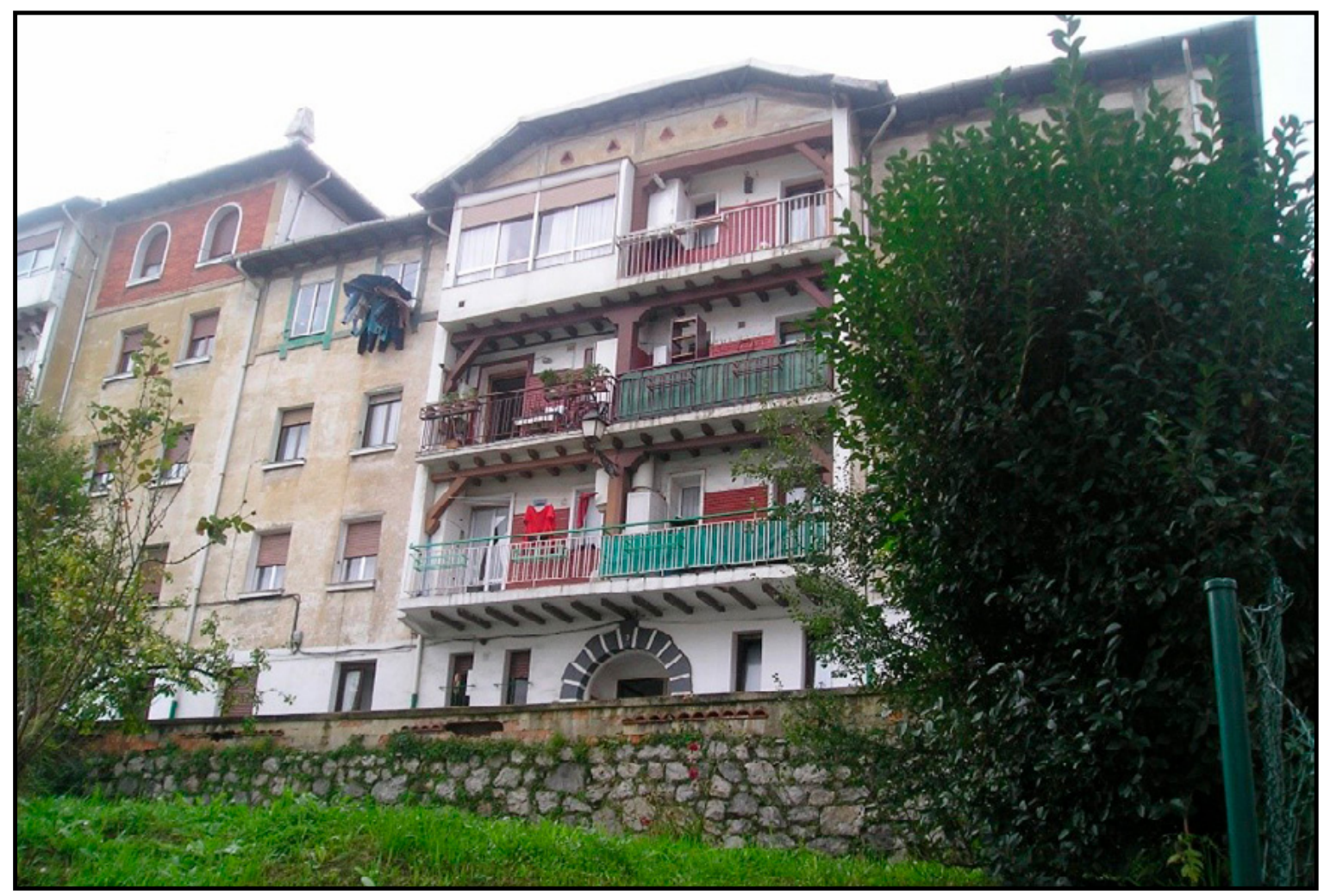

Figura 7. Casas del Poblado de Pescadores de Santurtzi (se observa el cierre del balcón en el tercer piso, modificaciones frecuentes que han ido cambiado la fisionomía original de estilo neovasco. 2.11.2009).

Este poblado en un principio estaría formado por cuatro bloques con 26 domicilios cada uno, ampliado más tarde a finales de los años sesenta. Son años en los que el ambiente y la situación política, propios del régimen franquista, apremian a rendir pleitesía. Por lo tanto, el poblado recibirá oficialmente el nombre de "Marqués de Valterra". En supuestas palabras del Patrón Mayor de la cofradía, Luis Marcos Cruz Zugasti, y su secretario Gerardo Castańos Ruiz, en honor y agradecimiento de la clase pescadora al: "Excm" Sr. DIRECTOR COMISARIO DEL INSTITUTO SOCIAL DE LA MARINA, que con cariño paternal viene dando cumplimiento a los deseos de nuestro invicto Caudillo a favor de los pescadores de bajura" (M.C.P.S., 1951, pp. 2-3).

En esta línea, cada bloque del pequeño nuevo barrio pescador llevará respectivamente los nombres honoríficos de "Grupo Girón (ministro de Trabajo), "Riestra" (gobernador civil provincial), "Diputación” y "Ayuntamiento", estos dos últimos, como reconocimiento a la aportación moral y material de los citados Organismos para la realización de tan meritoria obra a favor de los modestos productores del mar en la que también han colaborado con gran entusiasmo el $\mathrm{Excm}^{\circ} \mathrm{Sr}$ Comandante Militar de Marina de Bilbao, Dn. José Luis de Rivera y Egea y el Sr. Ayudante de Marina de Portugalete, Dn. Elías Fernández Gracia (M.C.P.S., 1951, p. 3).

Las viviendas se adquieren por medio de un Crédito Marítimo del Instituto Social de la Marina, amortizable a cuarenta ańos, pagado con sus rentas mensuales. Todo ello en un ambiente social y político en el que son de obligado cumplimiento los parabienes hacia las autoridades del régimen dictatorial franquista en el $\operatorname{poder}^{28}$ (M.C.P.S., 1951, pp. 2-3).

28 Como indica Alegret (2017, p. 282), a nivel estatal ya en el año 1942 "la dictadura impuso al sector pesquero 
En 1953 se vuelve a producir un descenso en el número de embarcaciones adscritas a la cofradía, quedando formada la flota por 25 pesqueros, ${ }^{29}$ volviendo a reducirse en tres al ańo siguiente. Aunque los resultados productivos mejoran en cifras, la cofradía santurtziarra toma conciencia de las dependencias respecto al mercado que se van estableciendo y en buena medida van atrapando a los pescadores. En este sentido, la institución califica el balance anual de poco optimista, consciente del "elevado valor de la Raba” (en relación con la escasez de la sardina) y resto de factores necesarios para llevar a cabo la pesca, reconociendo explícitamente, los

precios muy elevados de cuantos elementos son necesarios para la producción pesquera como son la cordelería, artes de pesca, motores, embarcaciones, etc. que dejan reducida a su mínima expresión el beneficio de Armadores de embarcaciones y pescadores los que por toda compensación resultan a fín de campańa o costera, con el equivalente de un jornal rondando en la miseria (M.C.P.S., 1953, p. 1).

No es fácil gestionar en estas condiciones. Este tipo de situaciones redundan directamente en la misma institución que, a pesar de su carácter corporativo y nivel de autogestión, es consciente de su incapacidad a la hora de controlar los cauces competitivos necesarios con los que alcanzar los beneficios

un modelo único de organización que se ajustaba a su ideología fascista", quedando constituidas las cofradías como "formas organizativas únicas, vinculadas obligatoriamente al sindicalismo vertical del régimen y con una estructura organizativa de representación de carácter corporativo", donde "se institucionalizó la intervención directa del Estado en el sector pesquero, mediatizándolo políticamente", intento este último que en Bizkaia y Gipuzkoa solo cuajaría relativa y formalmente.

29 Barcos integrantes de la flota del puerto santurtziarra, ordenados según las cantidades de pescado, de mayor a menor, vendido en el puerto de Santurtzi: San Pedro, Amaya, Mari Tere, Torrontero, Ignacio Urtiaga, Izazkungo Ama, Agur Miren, Virgen del Chanteiro, Gaviota, Akarregui, Loli Mila, Jesús Ignacio, Dos Amigos, Paloma Sport, Mari Begoña, San Francisco de Asis, Felipa, E, Virgen de Begoña Mariaren Biotza, Juan Andrés, Juan Angel, Arrizabalaga, Mari, y Nela. suficientes en pro de sus asociados. Se ratifica la situación, considerada del mismo tenor para la misma cofradía que debe afrontar el aumento del capítulo de gastos, cada día más elevado, aspecto unido a la disminución de pescadores, quienes buscan trabajos más estables, menos expuestos a los peligros de un medio como el marino y, en definitiva, considerados más beneficiosos, "confirmando nuestro pesimismo el hecho de que cada año es menor el número de embarcaciones y por consiguiente el de pescadores, los cuales se van colocando en Factorías y trabajos de Empresas terrestres ante el agobiante problema actual de la vida pesquera" (M.C.P.S., 1953, p. 1).

Años más tarde se sigue corroborando, en detrimento de la pesca, la falta notable de personal pescador, debido nuevamente a "la facilidad de colocación en empresas fabriles y Servicios Portuarios con jornales más positivos y remuneradores que los que se obtienen en las faenas de pesca”, hecho que lógicamente dificulta a los armadores disponer de las dotaciones necesarias para sus embarcaciones (M.C.P.S., 1956, p. 2). Sin embargo, no tardarán en ir apareciendo nuevos indicios y medios cuya aplicación propiciará un aumento en las cantidades vendidas.

No es fácil competir con el mercado de trabajo abierto y propiciado por la alta industrialización en esta zona del País Vasco, que además viene a coincidir con las oportunidades laborales de un puerto tan activo como el de Bilbao. Junto a esta competencia propia de un mercado laboral al alza, como decíamos, hay que considerar las condiciones y los propios riesgos implícitos en el oficio pescador:

En el mes de junio tuvimos la desgracia de que la embarcación AVE MARIA SANTISIMA, propiedad del armador asociado D. Federico Gonzalez [sic] Arrondo, fuese a pique a causa de un incendio a bordo, a la altura de Zumaya. Afortunadamente no hubo que lamentar desgracias personales, gracias a la serenidad del patrón y de la disciplina de su dotación, y la eficaz e inmediata ayuda prestada por la embarcación NUEVO MONTE HERMOSO, atendiendo a sus llamadas de socorro (M.C.P.S., 1978, p. 2). 
Volviendo sobre el proteccionismo propio de las cofradías, en esta década además del interés por conseguir más ventas y mejores precios, se procuran suministros ventajosos para los asociados (raba, gasolina, gasoil, aceites y grasas, cordelería, etcétera.). Los "socorros mutuos" también ocuparán una faceta primordial, aunque la intervención de instancias públicas irá descargando el peso de esta responsabilidad, por ejemplo, por medio de subvenciones provenientes del Instituto Social de la Marina. Siguiendo este parágrafo se continúan atendiendo las "bajas corrientes de enfermedad" (algunas crónicas), la "asistencia médico-farmacéutica de pescadores mayores de 65 ańos y viudas excluidas del Seguro de Enfermedad de los Pescadores de Bajura". Junto a estos capítulos sociales sigue en pie la "Sección de Ancianidad", aunque se empiezan a dedicar para este fin las subvenciones del citado Instituto, proyectándose en esta época también la creación de la Mutualidad Nacional de Previsión Social (M.C.P.S., 1953, p. 3).

\section{Precios, incertidumbres y nuevos indicios de modernización}

La influencia y el control estatal desde instancias externas se irán haciendo notar cada vez más claramente. Aunque las cofradías de pescadores continúan gestionando permanentemente la actividad, la incidencia y dependencia exteriores se van haciendo más patentes en su seno. Bajo la incidencia del franquismo y sus iniciativas sociopolíticas, se ha asumido obligatoriamente el modelo sindicalista vertical impuesto por el régimen a nivel estatal. En Santurtzi, la misma denominación oficial delata formalmente esta situación: Cofradía Sindical de Pescadores "San Pedro" de Santurce. Patrones y armadores ocupan una posición predominante, ahora bajo imposición sindical vertical, respondiendo a un modelo productivo que ha quedado muy lejos del artesanal. La cofradía santurtziarra sigue presentando anualmente su Memoria o ejercicio de las actividades realizadas, "expresando en cuadros estadísticos la situación económica final del año" y considerando como factor más importante la "producción pesquera". ${ }^{30}$ Esta

30 La Junta Directiva estaba conformada por Pedro Julio Lucena Fernández, presidente (patrón y armador del Amaya); Jesús Fadrique, vicepresidente; y los vocales cuestión se aborda siempre en primera instancia, centrada a lo largo de los ańos principalmente en la venta del pescado (M.C.P.S.,1963, p. 2).

En 1963 la problemática de la sardina ha ido quedando cada vez más lejos de la preocupación anterior y ahora, aunque las ventas en general disminuyen en cantidad, se compensa con el valor adquirido por la anchoa de un "tamańo y calidad especial para salazón". ${ }^{31}$ En este puerto y en otros a lo largo del litoral vasco la conexión con la industria conservera se hace notar. Por ejemplo, se subastarían en la lonja de la cofradía santurtziarra $634.133 \mathrm{~kg}$, un $34,25 \%$ menos que el año anterior, aunque con un valor monetario un $10,5 \%$ mayor. Por otra parte, aumentarían las ventas de bonito y de chicharro, cotizados sin embargo a precios más bajos. Este mismo año se haría notar el incremento en las ventas de especies como la caballa (o verdel) (Scomber scombrus), en esa época "poco apreciada para su consumo en fresco, pero de excelente resultado para conserva" (valoración que cambiará años más tarde). ${ }^{32}$ Las preocupaciones de la institución y la de los armadores de los barcos más productivos giran en torno a los precios alcanzados en el mercado, ocupando un lugar destacado las fábricas conserveras.

Tanto la cofradía de Santurtzi como las demás pretenden absorber el máximo de ventas posibles. Se trata de polarizar un momento clave de la distribución del pescado que comienza con las subastas. A cada cofradía le importa en primera instancia realizar el mayor número de ventas y alcanzar los

Félix Rodríguez Piedra (patrón y armador del Izazkungo Ama), Julián Hule Larrauri, Pedro Ruiz Gutiérrez, Celestino Sánchez Urrutia (armador y patrón del José Javier), Ernesto López Benítez y Ángel Urtiaga Beldarrain (armador y patrón del Tobaneku). Y Ramón Lachen Gracia, secretario/contador. Los patrones/pescadores, con el paso de los años y en función de nuevos intereses económicos y productivos, irán sustituyendo los barcos indicados por otros nuevos y de mayor capacidad, bien de nueva construcción o comprados en otros puertos.

31 El precio medio adquirido para esa especie en 1963 sería de 9,40 Pts/kg lo cual supuso, en comparación con el año anterior, una subida de casi un $75 \%$.

32 El verdel se diferencia de la cuerva o makarel (Scomber colias), apuntado a partir de los años sesenta en las ventas de Santurtzi. 
precios más altos posibles. En ello redundarán tanto sus beneficios como los de los propios cofrades. La tendencia vendrá marcada por dichos precios, según la cual los patrones de cada embarcación tratarán de introducir sus pescas en aquellas lonjas donde sean más favorables, rompiéndose cuando no interesa la tendencia a vender en las cofradías de procedencia. En este sentido los pesqueros de Santurtzi, al encontrar mejores precios en su propia lonja, comprobamos que acuden más asiduamente a su propio puerto que en años anteriores, actitud coincidente con la de un buen número de barcos forasteros. En consecuencia, por ejemplo, en 1963 el balance del pescado vendido por los barcos locales sería un 31\% mayor comparativamente con el ańo anterior. Este interés y el deseo por mantener esta tendencia favorable quedaba reflejado en un augurio para el año siguiente expresado desde la cofradía, con la esperanza de poder mantener el ritmo de ventas marcado:

$\mathrm{Al}$ encontrar mejores precios, las embarcaciones santurzanas han acudido más asiduamente a nuestro puerto para vender sus pescas, habiéndolas incrementado en más de dos millones en relación con el pasado año. Esperamos que el próximo no tengan necesidad de desplazarse a otros puertos más que en contadas ocasiones, lo que supondría un gran beneficio para la Cofradía y sus asociados (M.C.P.S., 1963, p. 2).

Como vemos, la incertidumbre ante la presencia de peces en la mar y luego ante las ventas de la pesca son componentes del carácter propiamente aleatorio de la pesca de bajura ya aludido. Esto a pesar de las nuevas tecnologías que han ido apareciendo y componentes para las redes como el nylon, aspecto que supondrá, no obstante, una ventaja más en aras de mejores resultados. Pero mantener los niveles de éxito no será siempre posible, entrando en competencia los principales puertos en los que se realizan las correspondientes ventas. Los pescadores tenderán a acudir a aquellas subastas y lonjas en las que los precios sean más ventajosos con el fin de obtener el máximo rendimiento a su trabajo.

\section{Progresión, avances tecnológicos y ambicio- nes inalcanzables}

En los ańos sesenta en Santurtzi el número de embarcaciones presentes oscila en torno a la veintena. Ya desaparecido definitivamente el uso de la gasolina, ahora todas emplean motores de gasoil. Tecnológicamente estamos ya en un momento cada vez más distanciado de los anteriores, situación que seguirá redundando en el aumento de la productividad. En 1961, por ejemplo, en febrero se alcanzan ventas hasta la fecha impensables para un mes en el que antes las capturas eran prácticamente nulas. Se obtienen buenos resultados, en una confluencia por una parte "del tiempo primaveral" de los primeros meses del año y "los modernos sistemas de capturas con la utilización de sondas acústicas para la localización del pescado". Este aspecto representa una diferencia importante "ya que anteriormente debían esperar a que éste se mostrase en la superficie" (M.C.P.S., 1961, p. 1).

A estos indicios propios de una modernización cada vez más progresiva, se irán sumando otra serie de acciones, destacando la puesta en marcha de una fábrica de salazones, montada por la Federación Sindical de Cofradías de Pescadores de Vizcaya. Atraerá a las embarcaciones, vendiéndose a través de la cofradía cantidades muy significativas de una especie altamente valorada como la anchoa. La fábrica propiciará incluso momentos récord de ventas, como sucedía en el mes de mayo de 1962. Pero al mismo tiempo la mayoría de los pesqueros locales intensifican sus ventas en otros puertos vascos como Bermeo, Ondarroa, San Sebastián, Getaria, Pasaia y el vecino Castro. Incluso acuden también a otros más alejados en el Cantábrico como Laredo, Santoña, Santander, Colindres, San Vicente, Avilés, Gijón y Ribadesella y A Coruña. ${ }^{33}$

33 Se trata del Arauca, Arcocha Balenciaga, Balenciaga, Cid Campeador, Echevarría Hermanos, E, Imanol, Iru Aiztak, José Javier, Mari Tere, Monte Hermoso, Nazareno, Nuevo Bracamonte, Santa Clara de Asis y Tobaneku. Solamente venden en Santurtzi sus pescas las embarcaciones Joven Panchonera, Jesús Ignacio, Loli Mila y San Francisco de Asis. 
En síntesis, nos encontramos en una década de patentes avances y resultados en una dirección continuamente progresiva, a los que se suma la construcción y entrega otra vez de nuevas viviendas en un terreno segregado del Poblado de Pescadores (a cargo de la constructora Fuentes S.A., iniciadas en 1968 y terminadas en 1969); $;^{34}$ la creación en forma cooperativa de un almacén de efectos navales con el fin de obtener precios sensiblemente mejores para los pescadores (años más tarde arrendado: Efectos Navales Ferromar); y la puesta en marcha de la Cooperativa de Cofradías de Pescadores de Vizcaya influyendo en el mantenimiento e incremento de las ventas y por lo tanto en los beneficios contabilizados por la cofradía santurtziarra.

También se retoman relaciones para posibilitar el transporte de pescado por tren con la compañía RENFE (Red Nacional de Ferrocarriles Españoles), aspecto que finalmente se consigue. En general estamos ante un momento de claro progreso que se confirma, entre otros factores, con la aparición de una demanda cada vez mayor de pescado "con destino principalmente a su industrialización", lo cual se espera continúe en ańos venideros por parte de la cofradía. Además, tal como se reconoce desde la institución de la propia modernización de los barcos, "otras de las causas de la mejoría experimentada hay que apuntarla en el haber de la progresiva modernización de nuestra flota, no solamente en cuanto al tonelaje y fuerza, sino también en la mejor preparación para su cometido, con utilización de artes de pesca de nylon y modernos equipos detectores" (M.C.P.S., 1966, p. 3).

Junto a esta línea de resultados y avances positivos, además reaparece la sardina (aunque pequeña o parrocha) en cantidades significativas. A todo ello se suma finalmente la creación de la Casa del Pescador.

34 El poblado exigirá mantenimiento y reparación (pavimentación de terrazas y de los accesos, blanqueo, etcétera), asumido desde la cofradía. No obstante, este año y en época de bonanzas se plantea la necesidad de que pasen a ser "propiedad de los beneficiarios, abonando las cantidades pendientes de amortización, estando en trámites los medios para realizarlo, si es que se considera conveniente por los interesados".
Estamos ante una constante adecuación a unas necesidades productivas cada vez mayores, más ambiciosa y en plena pujanza. Los barcos se han ido modernizando, sobre todo en connotación con la industria conservera (bonito y anchoa) y se siguen mejorando las instalaciones del puerto pesquero que en 1966 dispondrá, por fin, de un carro varadero, ansiado desde hacía tiempo. Ese mismo año la Junta de Obras del Puerto de Bilbao, a petición de los pescadores, pone en marcha obras de dragado con el fin de dotarlo de un "calado mínimo sobre bajamar equinoccial, de cuatro metros", obra que "permitirá la entrada y la estancia en perfectas condiciones, aún (sic) a las mayores y más modernas embarcaciones de Pesca" (M.C.S.P.S., 1966, p. 3). Esta misma dinámica, sin embargo, no coincidirá con lo que ocurre en los demás puertos del abra de Bilbao que quedan definitivamente obsoletos, incapaces de abrigar el mismo tipo de pesqueros que Santurtzi.

Esta marcha progresiva y de connotación industrial, sin embargo, no garantizará los objetivos locales. Parte de esta realidad es la dependencia de un mercado controlado desde instancias e intereses externos, afianzado desde la planificación económica desarrollista del sector, propiciada por las políticas del gobierno franquista. La industria conservera local llegará a un momento en el que se verá obligada a limitar sus compras, motivando "que las embarcaciones busquen otros puertos donde realizar mejores ventas" (M.C.S.P.S., 1966, p. 4).

Al mismo tiempo los armadores que han ido optando por pesqueros de mayor tamaño, ya a finales de los sesenta y durante los setenta, tendrán que seguir faenando y vendiendo también, lejos de las aguas cantábricas. ${ }^{35}$ No tienen más remedio que tratar de cubrir sus expectativas en momentos en los que, por ejemplo, falla la costera del bonito, a consecuencia de lo cual "cuatro de las más modernas de nuestras embarcaciones" se verán obligadas a "desplazarse al Sur a realizar la costera del listado en Algeciras" (bonito de vientre rayado). Es la única manera de hacer frente a sus inversiones, obtener rendimientos $y$, en

35 Es el caso de pesqueros santurtziarras como el John F. Kennedy, Brisas de Bermeo, Villa de Santurce, Nuevo Monte Hermoso y Maria Concepción, los que sobrepasan su marco de acción, que estaba en Asturias y Galicia, para dirigirse a Algeciras y Castellón. 
definitiva, cubrir los objetivos de capitalización en los que se ven envueltos los armadores. Como vemos, la situación realmente se escapa de sus manos. Los otros barcos, también grandes pero que no se ven precisados a acudir tan lejos, siguen faenando principalmente en función de las conserveras que compran fundamentalmente anchoa, mientras que las "embarcaciones medianas", cuando falla el bonito como sucede por ejemplo en 1966, tienen que dedicarse a la pesca de "cabezo" (caballa, chicharro, boga, etc.).

La aleatoriedad no deja de ser una constante que afecta a las ventas, dándose ocasiones en los que tanto barcos forasteros como santurtziarras dejan de acudir a Santurtzi, en función de sus cálculos e intereses, en detrimento de las ganancias locales. Por ejemplo, habrá momentos significativos al respecto en los que primará el ahorro de tiempo y de dinero en combustible. La pesca no siempre estará en las costas de la cofradía y, a veces, las embarcaciones "por no perder días de mar, han arribado a otros puertos más cercanos al pesquero", como Getaria y Lekeitio (M.C.S.P.S., 1967). También influirá la falta de concurrencia de compradores en la lonja santurtziarra. Y una cosa llamará a la otra en una cadena productiva en la que, como vemos, se terminan gestando menos ventas de pescado y menores ventas de hielo y, por lo tanto, menos utilidades.

Esta dinámica proseguirá en la década de los setenta a cuyo comienzo, no obstante, la anchoa llega a la bahía de Santurtzi. En estos años todavía es una especie abundante que, sin embargo, entrará en una situación realmente crítica en años venideros a causa de factores biológicos y ambientales, pero sobre todo por su sobrexplotación. A principios de esta década se ha producido un descenso en el número de asociados -que en 1971 son 141, bajando a 105 en 1978-. El número de barcos también descenderá paulatinamente. El puerto santurtziarra ha entrado en un período de recesión que también se refleja en el descenso del número de pesqueros adscritos a la cofradía. De los 27 a comienzos de los años sesenta, y los 28 pertenecientes en 1970 , se ha pasado en 1978 a tan solo 14 pesqueros. Esta situación tiene un punto crítico en 1979, año en el que la cofradía se ve obligada a efectuar un reparto entre sus miembros para paliar el mal momento económico por el que se pasa. La flota se reducirá un poco más aún en 1982, contando con 13 pesqueros, situación que se mantendrá en los años venideros.

\section{Divergencia entre formas productivas y situación actual}

La situación en el sector de bajura se va a configurar de manera diferencial respondiendo a formas de producción distintas. Esto se traduce en la distinción entre unos barcos y otros, referente a las especies capturadas, las cantidades vendidas, la posibilidad de acudir a lonjas más remotas pero más competitivas en cuanto a precios, la capacidad de faenar en zonas más alejadas del puerto base, así como en necesidades como la de tener o no que salir a pescar fuera del Cantábrico, entre diferentes expectativas económicas. Esto confluye en una diferenciación de carácter tecnológico en la que encontramos distintos tamaños y medidas en las embarcaciones, arqueos, potencias, tipo de motores y equipamiento en general. ${ }^{36} \mathrm{Y}$ actualmente desemboca en una separación básica establecida entre embarcaciones de artes mayores (que emplean fundamentalmente el cerco o bolintxi) y de artes menores (que utilizan principalmente redes de enmalle, palangres y nasas), entre las cuales difieren también las relaciones de producción. ${ }^{37}$

36 Los barcos de artes menores presentan en esos años, esloras que oscilan entre los 7,45 m del pesquero llamado 33, y los $12 \mathrm{~m}$ del Alegría, ambos también de menor y mayor potencia en cuanto a los motores: $40 \mathrm{CV}$ y 120 $\mathrm{CV}$, respectivamente. Los tamaños de los barcos de artes mayores difieren entre los 23,80 m del Mari José I y los 13,60 del Gure Ama Gelaxi, y en cuanto a los motores encontramos el más potente en el Nuevo Monte Hermoso, de $365 \mathrm{CV}$, y el de menor potencia en el Gure Ama Gelaxi, de $128 \mathrm{CV}$.

37 La convivencia de "secciones" productivas diferentes, que en el caso santurtziarra se limita a dos (cerquerosrederos), también ocurre en otras cofradías a nivel estatal, en las que se constata la existencia de "dos, tres, cuatro o cinco secciones que se reparten el poder" (Alegret, 2017, p. 288). No obstante, en nuestro caso los barcos de artes menores, en los últimos años y tal como hemos comprobado participando directamente (embarcación Ilunber eta Iskander, campaña del 2008), faenan conjuntamente con las de artes mayores durante la temporada del verdel, con sus respectivas capacidades productivas pero confluyendo en intereses económicos en cuanto a cuotas de captura, precios y comercialización. 


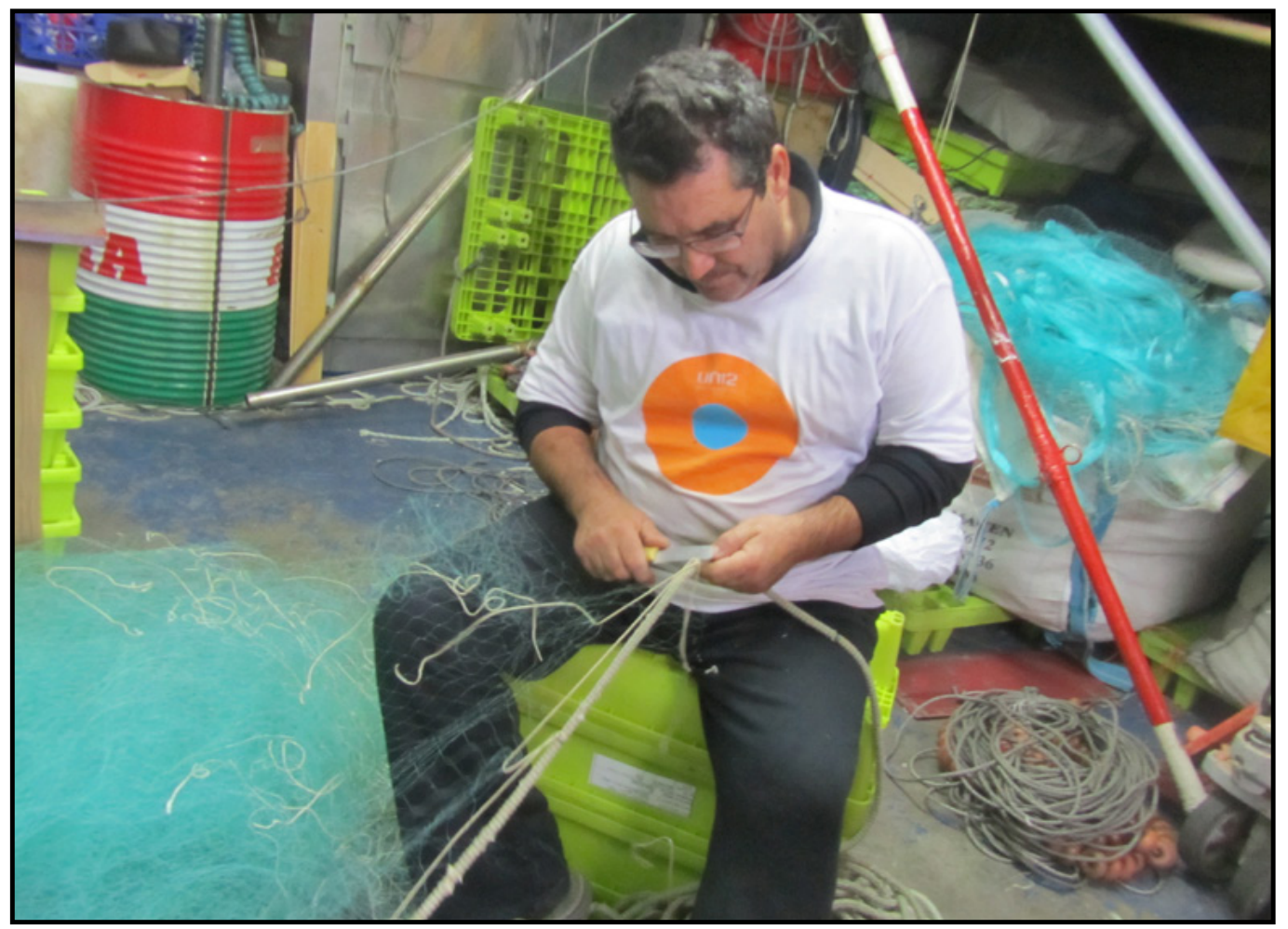

Figura 8. Tejido de redes en la bodega del pesquero de artes menores Ilunber eta Iskander (Santurtzi. 15.11.2013).

Una clarificación más económica nos lleva a comprobar que estas diferencias se traducen fundamentalmente en las particularidades de cada forma de producción, donde una parte de los armadores optan con claridad por capitalizar al máximo sus inversiones, accediendo a tecnologías más caras y complejas, y a embarcaciones de mayor tonelaje, mientras la otra se conformará con obtener las ganancias suficientes con las que mantener sus pesqueros, los aperos de pesca y el ámbito doméstico y familiar de quienes ostentan la propiedad y su tripulación. Se trata de dos concepciones económicas que no coinciden: una más ambiciosa y claramente tendente a una explotación más intensiva del medio, y otra más moderada y con una incidencia sobre este mucho menor. Los primeros son más acordes con el modelo productivo capitalista, pero afectos a un mercado cuyo control no depende directamente de ellos mismos y de una legislación normativa que tampoco está en sus manos. Los segundos se muestran en una situación que se identifica con una pequeńa producción de mercado, articulados al modo de producción capitalista, pero con otras formas de actuación, objetivos, expectativas e intereses, con una implicación total de los armadores en el proceso de producción (desde, por ejemplo, la extracción, venta, reparaciones, pintura, gestión documental, etcétera, hasta el tejido de las redes y la fabricación de los aparejos).

Las artes mayores se limitarán a un número de especies más concisa, respondiendo a un mercado de mayor escala y proyección, cuyo pescado es absorbido por mayoristas, grandes centros de distribución y fábricas de conservas. Pescan principalmente bonito, anchoa y verdel. Por su parte, en lo que respecta a las artes menores, seguirán la vía de la especialización, con un abanico de pescados bastante más amplio, dirigido a un mercado atendido más directamente, más específico y local. Estos pescadores van a mostrar su interés por especies como faneca (Trisopterus luscus), chicharro (Trachurus trachurus), pantxito (Pagellus acarne), cabra (Escorpaena corpus), salmonete (Mullus surmuletus), pescadilla 


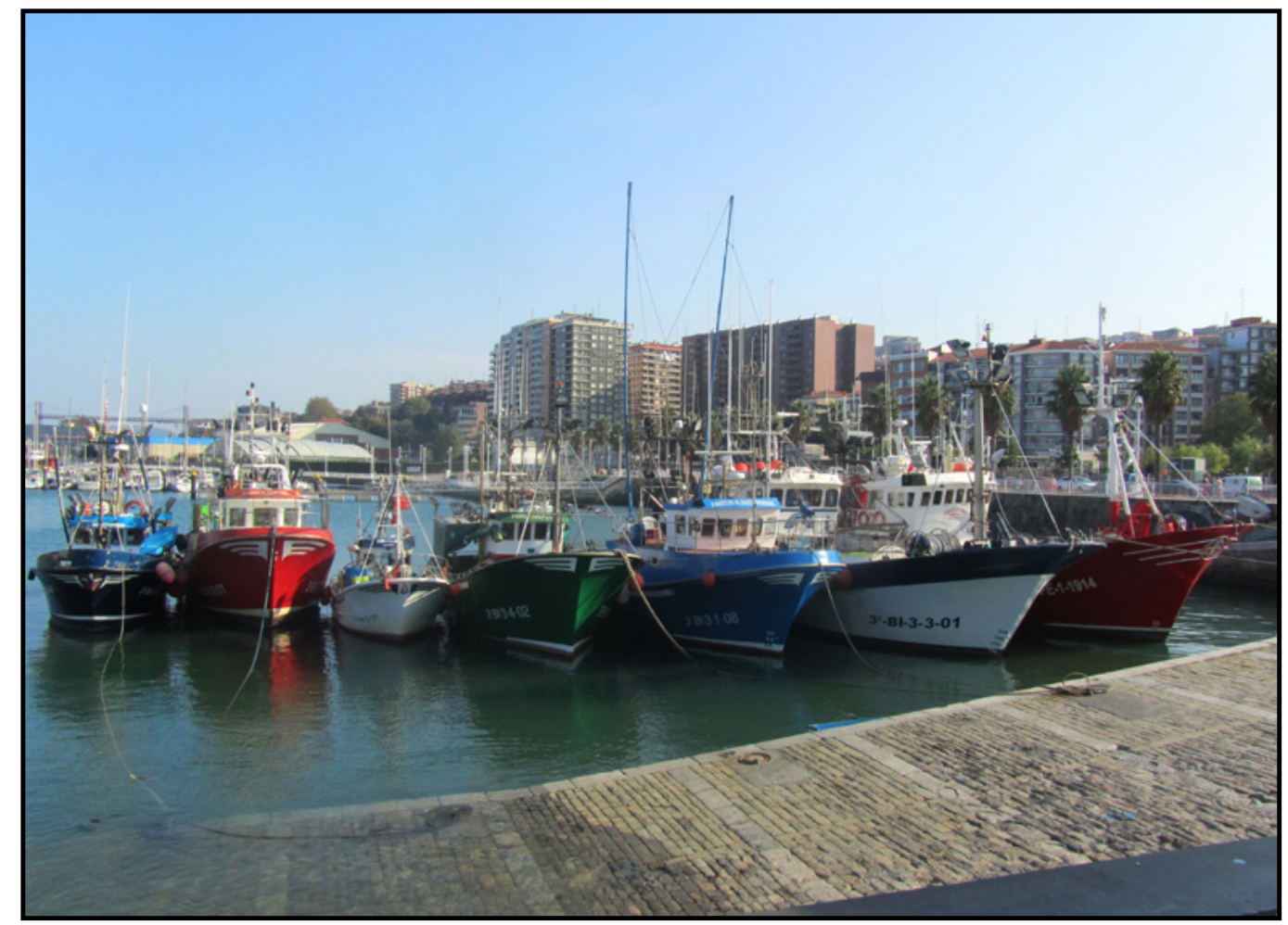

Figura 9. Pesqueros amarrados en el Puerto de Santurtzi; de izquierda a derecha: Gorostiaga Hermanos, Gorostiaga Hermanos II, Martin Albizu Anaiak, Hiru Anaiak, Rokillo, Laura y Cristina y Sabadeo (29.09.2014).

(Merluccius merluccius). También la sardina, boga y cuerva. Con sus nasas capturan mariscos como la nécora (Macropipus puber), bogavante (Homarus gammarus), buey (Cancer pagurus) y centollo (Maja squinado). Como vemos, se trata de una gama bastante más variada, que se venderá sin ningún tipo de intermediación, habitualmente de manera directa en el mismo puerto.

Actualmente y en consonancia con la reducción de barcos pesqueros de bajura en todo el País Vasco, que entre 2007 y 2010 llega al 34\%, se hace cada vez más evidente la presencia de embarcaciones modernas de tipo polivalente. ${ }^{38}$ Sus cascos son de acero o fibra y responden a un modelo productivo capitalista a pequeńa escala, con tripulaciones menores y equipamientos y condiciones más actualizados y eficaces. Aunque se siguen enmarcando en las artes menores, tanto unas como otras responden a una ti-

38 Por modalidades la representación en 2010 era la siguiente: artes menores 76 pesqueros (38\% de la flota), cerco $59(29,5 \%)$ pología de barcos muy modernizados, más seguros, generalmente de cascos de fibra y sustitutos definitivamente de los anteriores construidos en madera. Esta confluencia coincide con otra más significativa, tal y como es la participación conjunta, en la medida de las capacidades y objetivos de cada modalidad, en las mismas campañas como por ejemplo la del verdel. Pesquería implementada gubernamentalmente en los últimos años, en parte para suplir la escasez de anchoa objeto de vedas y limitaciones.

En Santurtzi, y como colofón a nuestro recorrido cronológico, en estos últimos ańos contamos con una flota adscrita a la cofradía que da trabajo a 35 pescadores, compuesta por ocho pesqueros, todos diferentes a los que faenaban en la pasada década de los años noventa. Sus cascos son de poliéster, salvo el del Gorostiaga Hermanos II que es de acero. Este está censado en la modalidad de cerco o artes mayores, junto al Gorostiaga Hermanos. Sus potencias son de $330 \mathrm{CV}$ y $402 \mathrm{CV}$, respectivamente. También con arqueos de 73,88 TRB y 79,1 TRB; y esloras 


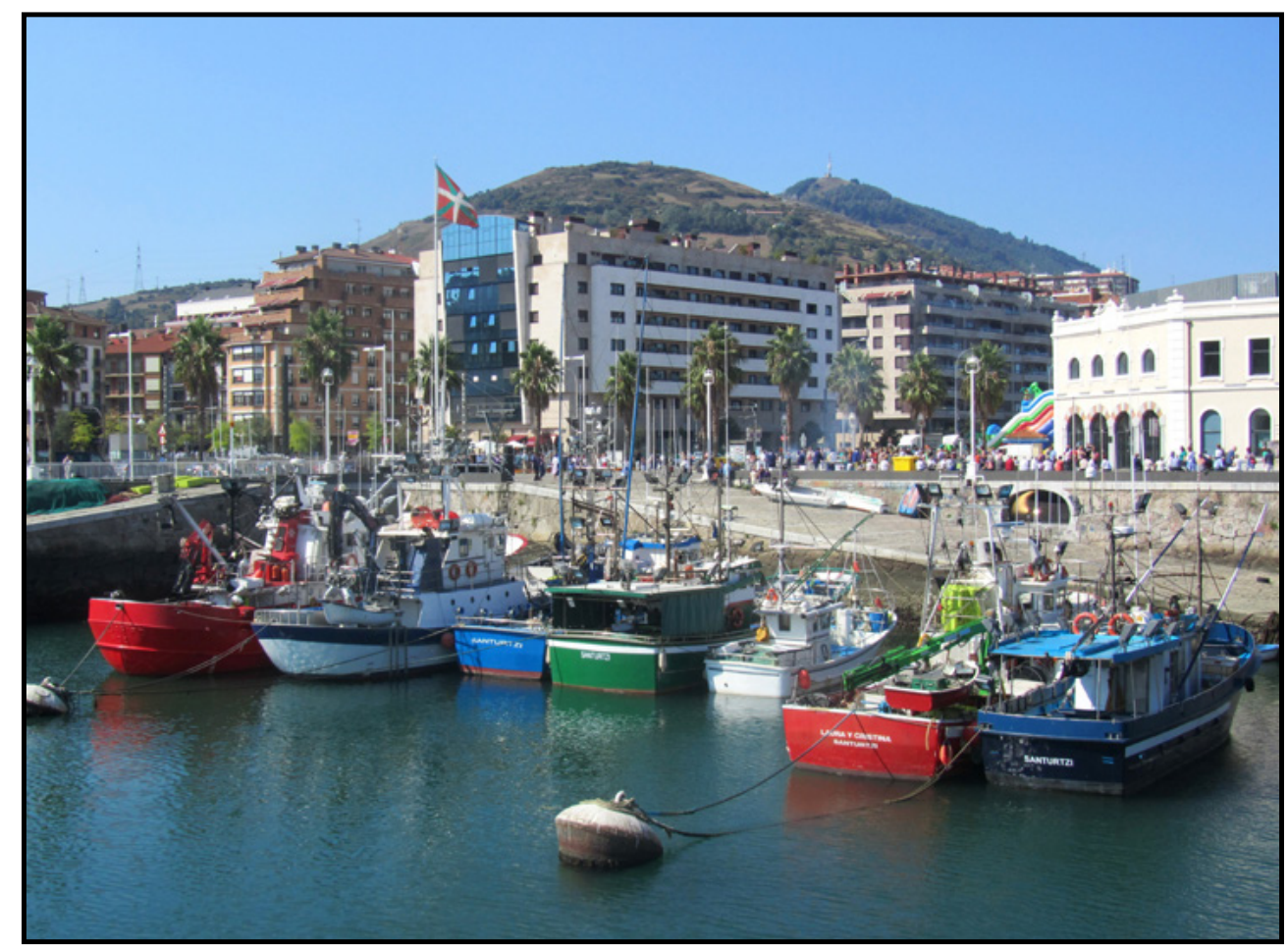

Figura 10. Pesqueros amarrados en el Puerto de Santurtzi vistos desde popa; de izquierda a derecha: Gorostiaga Hermanos, Gorostiaga Hermanos II, Martin Albizu Anaiak, Hiru Anaiak, Rokillo, Laura y Cristina y Sabadeo (29.09.2014).

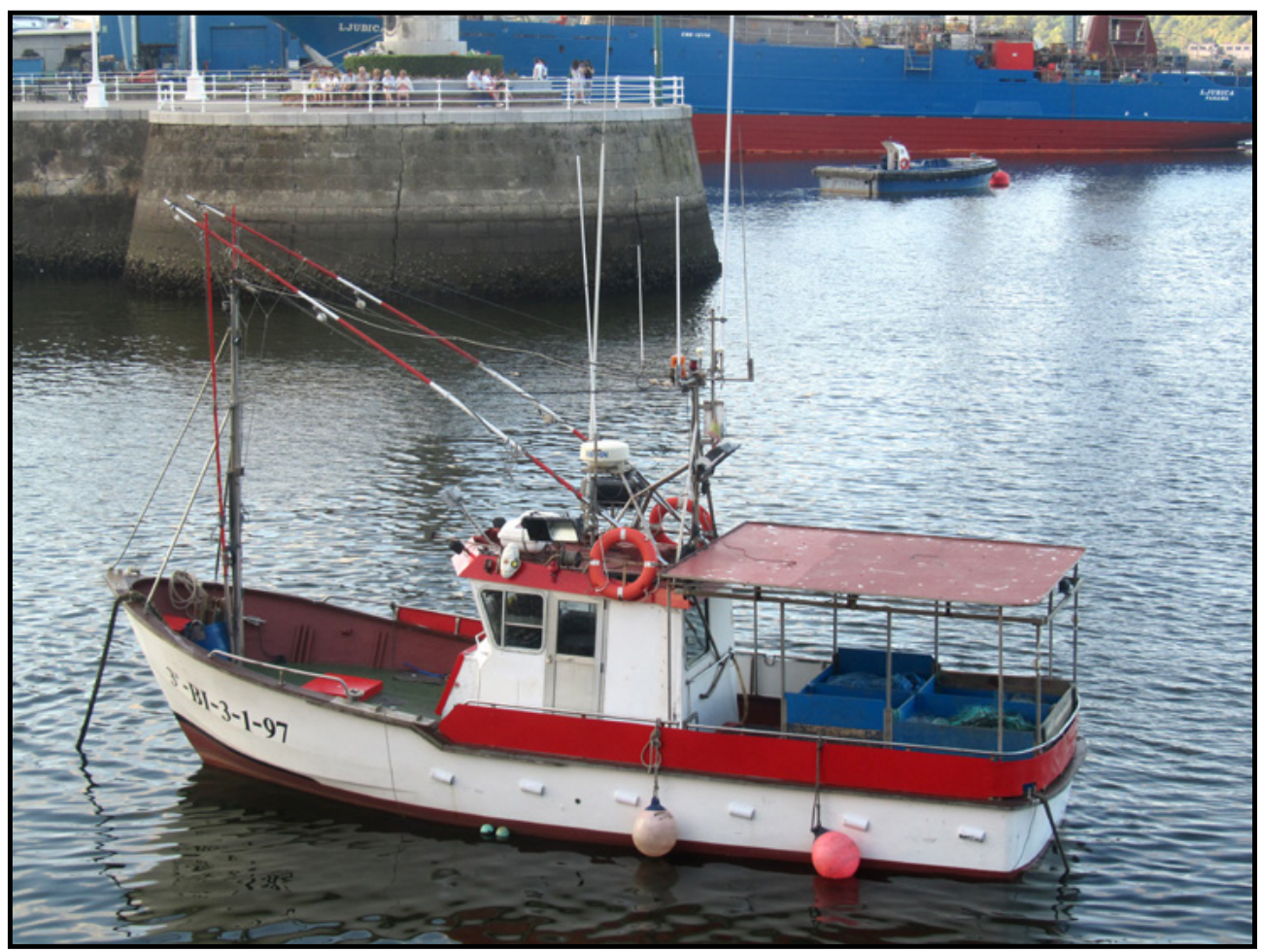

Figura 11. Pesquero de artes menores Ilunber eta Iskander. Puerto de Santurtzi (22.07.2014). 
de $24,2 \mathrm{~m}$ y $26,58 \mathrm{~m}$, respectivamente. Sus fechas de entrada en servicio respectivas son 2001 y 1990. Respecto a los barcos de artes menores, tienen como media una potencia de $120 \mathrm{CV}$, que oscila entre los $50 \mathrm{CV}$ del Ilunber eta Iskander y los $191 \mathrm{CV}$ del Sabadeo. El arqueo medio es de 20,58 TRB, oscilando entre las 4,9 TRB del Ilunber eta Iskander y las 49,17 TRB del Martin Albizu Anaiak. Presentan una eslora media de $12,37 \mathrm{~m}$, siendo la mayor la del Laura y Cristina (16,52 m) y la menor la del Rokillo $(9,61$ $\mathrm{m})$. Su media de edad es de 14,8 años.

\section{Conclusión}

Una vez llegados a la situación actual, podemos ya concluir este periplo que arrancaba en un momento cronológico, como el siglo XIX, en el que la cofradía se presentaba como institución con ciertas fortalezas que servirán de base para el posterior proceso de modernización de la profesión iniciado en el primer cuarto del siglo pasado. Estas se hacen patentes principalmente en la capacidad de gestión, defensa y atención social de los pescadores. La institución se muestra capaz de cohesionar en torno a ella a hombres y mujeres pescadores, quienes se ciñen a las exigencias y normas donde ya destacaban, como veíamos, las referentes a la venta del pescado y el pago de derechos. La respuesta y asunción al respecto será uno de los pilares gracias al cual se consigue mantenerla en funcionamiento con la implicación de todos los asociados.

Hemos comprobado la existencia de un caldo de cultivo que preparaba el camino para un cambio tan importante como el que trajo consigo la aparición de los primeros motores de vapor en la práctica pesquera de bajura. Para esas fechas, primeras décadas del siglo XX, los pescadores cuentan con una experiencia y capacidad de gestión primordiales, gracias a las cuales se irá viabilizando administrativamente esta nueva época. Además se consigue un puerto mejor preparado para asumir paulatinamente esta nueva fase productiva, con mejores instalaciones y el calado suficiente para barcos ahora de mayor tonelaje, a lo que se suma un nuevo edificio destinado a la cofradía. En estos años se pasa de una forma productiva que hemos señalado como artesanal y antigua, abandonando en poco tiempo los barcos descritos propulsados a remo y vela, para optar por embarcaciones motorizadas de vapor, de mayor volumen y capaces de acudir a pescar cada vez más lejos del puerto de Santurtzi.

La nueva situación supondrá un incremento productivo importante, sentando las bases para un nuevo impulso y período en el que las embarcaciones de vapor cederán definitivamente sus puntos de amarre, ya en los ańos cuarenta, a otras equipadas con motores de gasolina y poco después propulsadas con diésel. De esta manera se va entrando en una espiral que exige responder a la pequeńa capitalización del sector. Son años en los que se intensifica el trabajo y en los que la cofradía tendrá que ir haciendo frente a nuevas necesidades de tipo social, entre las que destaca el problema de la vivienda. Será capaz de impulsar la construcción de un nuevo barrio destinado a las familias pescadoras y también de seguir manteniendo la atención médica y las pensiones de jubilación, en un momento en el que ha perdido totalmente el poder de autogestión anterior. En este sentido deberá entrar en el cauce de las propuestas sociales del régimen dictatorial del momento, en un modelo único de organización franquista coincidente con un sindicalismo de carácter vertical.

Llegamos a una situación en la que se promociona la mejora de los medios de producción desde la cofradía, amparada paternalistamente por las instituciones afines al régimen franquista. Los armadores encuentran un apoyo administrativo, no obstante, conducente a nuevas vías de financiación en una clara preocupación por capturar cada año mayores cantidades de pescado y de conseguir su venta en la localidad. Se muestran iniciativas desarrollistas, llegándose a crear una fábrica de conservas y salazón y una nueva fábrica de hielo capaces de atraer importantes cantidades de pescado, tanto de los barcos de la flota local como foráneos. También se ofrece y llegan a cubrir los vacíos de la falta de formación profesional. Se debe responder a la normativa legal propia de una modernización que exige preparación formal certificada. Pero en su conjunto, esta dinámica deberá afrontar la escasez de especies importantes de alto valor en el mercado y la competencia exterior, aspectos ante los que finalmente la cofradía no podrá alcanzar resultados totalmente satisfactorios y en la que los armadores optan, no obstante, 
por entrar en esta nueva fase que implica mayores inversiones. Entre las vicisitudes detectadas destaca, por otro lado, el impacto de la industrialización de la región, que se irá convirtiendo cada vez más abiertamente en un atractivo laboral, en detrimento de la profesión pescadora.

Los pescadores finalmente deberán ir situándose en modelos productivos diferentes dentro del sector de bajura. Todos no serán capaces de entrar de la misma manera en una dinámica que exige inversiones y disponibilidad de capital para seguir siendo productivos. Es así como se entrará en una fase claramente palpable en los ańos noventa en la que se presentan dos formas de producción, con intereses, maneras de organización productiva, relaciones en el interior del proceso productivo, propiedad de los barcos y enseres, modalidades de pesca, tecnologías empleadas y especies capturadas, muy distintas. Se trata, por una parte, de una forma más cercana al modelo propiamente capitalista, practicado por los pesqueros de artes mayores, y de otra que responde a una pequeña producción de mercado. Esta distinción, aunque se seguirá manteniendo en la actualidad, irá diluyéndose levemente en algunos aspectos tecnológicos en simbiosis, como por ejemplo la participación conjunta en campañas como la del verdel. La cofradía santurtziarra seguirá ejerciendo como institución fundamental en un momento que podemos concluir, como muestra la evolución de los datos del caso analizado (extensible a la mayoría de las localidades vascas), de clara recesión para una profesión como la pesca de bajura en el País Vasco, a pesar de sus raíces históricas y tradicionales.

\section{Referencias citadas}

Alegret Tejero, J. L. (2017). Las cofradías de pescadores en España. En Nadal i Farreras, J. (Ed.). La ciudad y el mar. Estudios sobre una relación sólida en un medio líquido (pp. 281-289). Girona: ICRPC, Documenta Universitaria.

Apraiz Zallo, J. A. (1998). Carpintería de ribera y evolución histórico-tipológica de las embarcaciones de bajura en el País Vasco. De la vela al siglo XXI. Itsas Memoria. Revista de Estudios Maritimos del País Vasco, 2, 387-406.
Arbex, J. C., Galindo López, F. (1987). Pesqueros españoles. Madrid: Secretaría General Técnica del Ministerio de Agricultura, Pesca y Alimentación.

Arizaga Bolumburu, B. (2000). La pesca en el País Vasco en la Edad Media. Itsas Memoria. Revista de Estudios Maritimos del País Vasco, 3, 13-28.

Carbonell i Camón, E. (2010). El patrimonio inmaterial marítimo: la etnoclimatología. Reflexiones en torno a la relación del navegante con la naturaleza. Zainak. Cuadernos de Antropología-Etnografía, 33, 27-58.

Erkoreka Gervasio, J. I. (1991). Análisis histórico institucional de las cofradías de mareantes del País Vasco. Vitoria: Departamento de Agricultura y Pesca Gobierno Vasco, Eusko Jaurlaritzaren, Zerbitzu Nagusia/Servicio Central de Publicaciones del Gobierno Vasco.

Gabantxo Uriagereka, M. (2003). Atuneros congeladores: el cambio generacional y la transmisión de conocimientos tradicional. Zainak. Cuadernos de Antropología-Etnografia, 25, 33-36.

García-Orellán, R. (2007). El colapso del bacalao: la construcción de la memoria ayer y hoy. Zainak. Cuadernos de Antropologia-Etnografia, 29, 153-169.

García-Orellán, R. (2016). La pesca industrial y la emigración gallega en Trintxerpe, 1920-1970. Riev. Revista Internacional de los Estudios Vascos, 61(2), 354-387.

García-Orellán, R., Beobide Arburua, J. (2004). Hombres de Terranova. La pesca del bacalao (1926-2004). San Sebastián: Pasaiko Portua/Puerto de Pasajes.

Geistdoerfer, A. (2007). L'anthropologie maritime: un domaine en évolution: hors cadre traditionnel de l'anthropologie sociale. Zainak. Cuadernos de Antropología-Etnografía, 29, 23-38.

Huxley [Barkham], S. (1987). Los vascos y las pesquerías transatlánticas, 1517-1713. En Huxley [Barkham], S. (Ed.). Los vascos en el marco Atlántico Norte. Siglos XVI y XVII (pp. 26-210). San Sebastián: Etor Editorial.

Rubio-Ardanaz, J. A. (1992-1993). Inventario documental de la Cofradía de Pescadores San Pedro de Santurtzi, Bermeo. Udalerri eta Itsasoko Gaiei Buruzko Aldizkaria, 9, 187-269. 
Rubio-Ardanaz, J. A. (1997). La vida arrantzale en Santurtzi. Cambios económicos y socioculturales entre los pescadores de bajura (ss. XIX y XX). Bilbao: Ayuntamiento de Santurtzi.

Rubio-Ardanaz, J. A. (2002). Levantar la pesca, desplazamiento de técnicas tradicionales en el contexto del cambio en el modo de producción pesquero en el País Vasco. Zainak, Cuadernos de Antropologia-Etnografia, 21, 213-219.

Rubio-Ardanaz, J. A. (2006). Lemanes, sardineras y pescadores. Barcelona: Grafema.

\section{Fuentes documentales consultadas}

Escritura de contrato médico y sus bases, 1988 (Archivo antiguo documental de la Cofradía "San Pedro de Santurtzi”).

Libro de cuentas corrientes de la Cofradía de mareante de Santurce, 1846 (Archivo antiguo documental de la Cofradía "San Pedro de Santurtzi").

Memoria. Cofradía de Pescadores de "San Pedro" de Santurce. Ejercicios 1951, 1952, 1953, 1955, 1956, 1961, 1963, 1978, 1979. (M.C.P.S).

Memoria. Cofradía Sindical de Pescadores "San Pedro" de Santurce. Ejercicios 1966, 1967. (M.C.S.P.S.).

Memoria "Doneperi” Arrantzale Kofradia. Santurtzi. 1982. 